O'Connor, Fergal, Lucey, Brian and Aggarwal, Raj (2014) Rationality in Precious Metals Forward Markets: Evidence of behavioural deviations in the gold markets. Journal of Multinational Financial Management, 25-26. pp. 110-130.

Downloaded from: http://ray.yorksj.ac.uk/id/eprint/1441/

The version presented here may differ from the published version or version of record. If you intend to cite from the work you are advised to consult the publisher's version: http://www.sciencedirect.com/science/article/pii/S1042444X14000152

Research at York St John (RaY) is an institutional repository. It supports the principles of open access by making the research outputs of the University available in digital form. Copyright of the items stored in RaY reside with the authors and/or other copyright owners. Users may access full text items free of charge, and may download a copy for private study or non-commercial research. For further reuse terms, see licence terms governing individual outputs. Institutional Repository Policy Statement

\title{
RaY
}

Research at the University of York St John

For more information please contact RaY at ray@yorksj.ac.uk 


\section{Rationality in Precious Metals Forward Markets: Evidence of behavioural deviations in the gold markets}

Raj Aggarwal: University of Akron, 7380 Sherman Road, Chesterland, OH 44026, USA. aggarwa@uakron.edu

Brian M Lucey: (corresponding author): School of Business Trinity College Dublin 2 Ireland ; Institute for International Integration Studies (IIIS), The Sutherland Centre, Level 6, Arts Building, Trinity College Dublin 2 Ireland ; Glasgow Business School, Glasgow Caledonian University, Cowcaddens Rd, Glasgow, Lanarkshire G4 0BA, United Kingdom ; Faculty of Economics University of Ljubljana Kardeljeva ploscad 17 Ljubljana, 1000 , Slovenia blucey@tcd.ie

Fergal A. O'Connor School of Business Trinity College Dublin 2 Ireland ; Institute for International Integration Studies (IIIS), The Sutherland Centre, Level 6, Arts Building, Trinity College Dublin 2 Ireland;. York St. John's Business School, York St John University, Lord Mayor's Walk, York, YO31 7EX. fergal.a.oconnor@gmail.com

\section{$\underline{\text { Abstract }}$}

We offer the first examination of whether the gold forward rate is an unbiased predictor of the future gold spot rate. We find strong evidence that it is not, particularly at longer maturities. Building on Aggarwal and Zong's (2008) approach to allow for investor risk aversion, we then examine if these deviations from rationality can be explained by behavioural factors such as market optimism and over-reaction to news. We find that forecast errors in the gold market generally suffer from overreaction to observed spot price changes but underreact to outflows of gold from Exchange Traded Funds. Further, the forward premium is found to be a consistently optimistic estimate over the full sample. Finally, while the market mood is shown to vary greatly over time, swinging from pessimism in the 1990's to optimism after 2000, the forecast revision overreaction is found to be consistently stable over the full sample. These are significant, important, and consistent indications of seemingly non-rational behavioural effects in the gold forward market.

\section{Introduction}

In this paper we analyze data from the largest gold market. The London Over-The-Counter (OTC) Gold Market's depth and liquidity make it an important part of the global financial system with the value of spot and forward trading in, for example, 2011 worth approximately $\$ 13.5 \mathrm{tn}$ and $\$ 750 \mathrm{bn}$ per quarter respectively (Murray, 2011). This represented approximately 86\% of all gold trading in 2011 according to Lucey, Larkin and O'Connor (2013). The issue of the relationship between spot and forward prices is a significant one for market participants, whether from a hedging or a speculative perspective.

In this paper we offer the first assessment of the ability of the gold forward rate to act as a predictor of the future spot rate, assessing whether precious metals markets are characterised by rational expectations. If rational expectations hold true, the forward market provides an unbiased estimate of the future spot rate, with the two prices being perfectly positively correlated and with an expected value for prediction errors of zero. Results from other markets such as equity and foreign exchange have documented systematic deviations from rationality (Aggarwal et al, 1995). Surveys of the literature (e.g., Engle 1996) have been unsuccessful in explaining such deviations using foreign 
exchange models of risk premia such as the capital asset pricing model and trade frictions. Failure of this Forward Rate Unbiasedness Hypothesis (FRUH) could be as a result of one of two issues, or both.

Firstly the market may not be risk neutral as assumed by the FRUH. Over the sample examined here the spot price of gold on a given day is generally greater than the forward prices in the early part of the sample indicating a contango relationship, as shown in figure 1 . However it switches to backwardation regularly from 2008. This forward premium can be viewed as compensation for the cost of carrying gold in your portfolio. These costs include storage and insurance as well as the opportunity cost of interest forgone. A benefit can be earned from holding gold by leasing it. An earlier study by Kolb (1992) found that neither contango nor backwardation dominated for gold futures between 1957 and 1988. Keynes (1930) argued that forward prices will either be above or below the expected future spot depending on whether speculators hold short or long positions respectively. This is because they require a risk premium in order to hold purely speculative positions. As there is no long or short data on the forward gold market at any given time, here we will control for the general level of risk aversion in the market.

\section{[Insert Figure 1 about here]}

Or secondly, a number of behavioural factors could explain failures of financial markets to rationally anticipate future prices. These include behaviours such as systematic under or overreaction to news in the market; which has been documented in equities by Jackson and Johnson (2006) and in foreign exchange markets by Aggarwal and Zong (2008).

Evidence on the behavioural aspects of the gold market is more limited than would be imagined for an asset that has such an impact on the emotions of investors (among the few exceptions is Aggarwal and Lucey, 2007). This paper will attempt to apply and develop the behavioural analysis used by Easterwood and Nutt (1999) and Aggarwal and Zong (2008) to assess whether the precious metals markets are characterised by optimism or pessimism, and whether they over or under-react to new information. The information assessed here includes changes in the following variables: spot prices, forecasted spot prices, the forward premium, and changes in the holding of gold by Exchange Traded Funds (ETF's). We assess these possible behavioural explanations of the failure of the FRUH while controlling for investor risk aversion.

We also examine the evolution of the markets risk aversion and behavioural dynamics over time to assess whether the markets outlook is stable over time. Our data set contains a wider range of maturities than previous studies with 1, 3,6 and 12 month maturities used. This allows us to assess whether long run factors affect the short run and vice versa rather than solely looking at the issue for the same maturity.

Section 2 will provide a review of the literature on the FRUH and behavioural biases, Section 3 details the data used, Section 4 will present the methodology and results, and Section 5 will give the conclusions.

\section{The Spot and Forward Rates Relationship}

\subsection{The Forward Rate Unbiasedness Hypothesis (FRUH)}

The FRUH assumes that if rational expectations hold and investors are risk neutral the forward rate is an unbiased predictor of the expected future spot. It can be expressed as:

$$
E_{t}\left(s_{t+1}\right)=f_{t}
$$


where $E_{t}$ represents the expectation conditional on information available to the market $t, s_{t}$ is the spot rate and $f_{t}$ is the forward rate (Zivot, 2000). Baillie (1989) refers to this hypothesis as observable expectations. In levels we can express the hypothesis as:

$$
s_{t+1}=f_{t}+\epsilon_{t+1}
$$

Where $\epsilon_{t+1}$ is the rational expectations forecast error with an expected value of zero. This leads to a regression in levels which allows us to test for unbiasedness in the forward rate.

$$
s_{t+1}=\alpha+\beta f_{t}+\mu_{t+1}
$$

The null hypothesis is that $\beta=1, \alpha=0$ and $\mathrm{E}_{\mathrm{t}}\left(\mu_{\mathrm{t}+1}\right)=0$. As $\mathrm{S}_{\mathrm{t}}$ and $\mathrm{F}_{\mathrm{t}}$ are generally found to have unit roots testing the FRUH requires assessing whether $S_{t+1}$ and $F_{t}$ are cointegrated with a $(1,-1)$ vector.

Engle (1994) also shows the difference version of this regression equation as follows:

$$
s_{t+1}-s_{t}=\alpha+\beta\left(f_{t}-s_{t}\right)+\mu
$$

Where the null hypothesis that the forward premium is an unbiased predictor of the change in the spot rate is found to be true if $\beta=1, \alpha=0$ and $\mathrm{E}_{\mathrm{t}}\left(\mu_{\mathrm{t}+1}\right)=0$.

MacDonald and Taylor (1992) also suggest testing the efficiency of the forward market by using the forecast error (FE), the difference between the forward rate $\left(\mathrm{F}_{t}\right)$ and the realised spot rate at $t+1\left(\mathrm{~S}_{t+1}\right)$. The FE is regressed on lagged values of itself as in equation 2.5 below.

$$
s_{t+1}-f_{t}=\alpha_{0}+\sum_{i=0}^{p} \beta_{i}\left(s_{t-i}-f_{t-i-1}\right)+\mu
$$

With the null hypothesis $\alpha=0$ and $\sum_{i=0}^{p} \beta_{i}=0$. This provides a test of weak form market efficiency, as a finding against implies that using freely available market information it is possible to outperform the market.

\subsection{Evidence on Forecasting, the FRUH and Market Behaviour}

A large amount of research testing the FRUH has been carried out on the foreign exchange market. The theoretically elegant rational expectations hypothesis (REH) has very little or no support in practice. Estimates of $\beta$ for equation 2.4 are frequently and puzzlingly found to be closer to -1 rather than +1 required by the REH (such as Gospodinov, 2009). Froot and Thaler (1990) look at estimates of $\beta$ from over 75 papers and find an average value of -0.88 . While still not providing evidence to support the hypothesis, Frankel and Rose (1994) argue that an estimate of $\beta<0$ may only apply to floating exchange rate regimes, as when they look at European countries participating in the Exchange Rate Mechanism the find an estimate much closer to zero.

Evidence on whether spot and forward exchange rates are cointegrated is mixed. MacDonald and Taylor (1989) test for cointegration between the spot and forward rate for 10 sets of exchange rates over a 12 year period and find no strong evidence for cointegration. Hakkio and Rush (1989) test the UK Pound/US Dollar and the Deutsche Mark/US Dollar exchange rates and find that cointegrating relationships do exist. Aggarwal and Zong (2008) find mixed evidence when testing 9 currencies, but in general find against the idea that currency markets are characterised by rational expectations. Deviations from FRUH are particularly puzzling as they should provide opportunities for traders to profit from the deviations (Kritzman, 1993). 
Forecasts by equity analysts' also seem to fail the rational expectations test. Kang, O'Brien, and Sivaramnkrishnan (1994) find that analysts' forecasts are biased upwards. There has been conflicting evidence on whether analysts under- (Elliot, Philbrick, and Wiedman, 1995) or over-react to new information (Debondt and Thaler, 1990). Easterwood and Nutt (1999) find that analysts underreact to negative information and overreact to positive news indicating systematic optimism resolving inconsistencies in earlier work on the issue. Gu and Xue (2007) find that analysts over react to good news, but once earning uncertainty following extremely good news is controlled for, only their general under reaction remains. This evidence of biases in equity analyst's forecasts can however be at least partially explained by their economic incentives. To gain access to the companies they are following analysts' reports cannot be seen as negative and as sales employees they are incentivised to encourage customers to purchase stocks.

However, such perverse economic incentives should not exist in the forward markets for foreign exchange or precious metals where participant errors can result in financial losses. There have been many papers which have tried to explain the bias found in forward exchange rates. Engle's (1996) survey documents a number attempts utilising models that account for potential problems such as risk premia and trade frictions but they conclude that these have not resolved the issue. Other attempts have looked at peso problems and learning (Frankel and Rose, 1994) but the general conclusion is that forward currency markets do not fully conform to the FRUH remains (Aggarwal, 2004).

Recent work has examined if behavioural biases can help to explain this non-rationality across a number of markets. Amir and Ganzack (2006) find that security analysts under react to new information. Aggarwal and Zong (2008) find that forward exchange rates are characterised by systematic pessimism and under reaction to new information. Ball and Croushore (2001) look at macroeconomic news and find that market responses to new information on inflation are consistently pessimistic. Daniel, Hirshleifer, and Subrahmanyam (1998) explain the theoretical underpinnings of under-reaction as overconfidence by market participants who put too much weight behind their private information and fail to make full use of public information.

Keynes (1930) and Hicks (1939) argued that forward prices will either be above or below the expected future spot depending on whether speculators hold short or long positions. This is due to the risk premium they require in order to hold their purely speculative positions. Lewis (1989) examined predictions regarding the US Dollar using forward rates and attributed 50\% of the errors to a learning issue and the remaining 50\% to a risk premium. Mohanram and Gode (2013) find a strong link between the cost of equity, as a measure of risk, and analysts forecast errors for stocks. However Gurkaynak and Wolfers (2006) examine the market for macroeconomic derivatives and find only a very small risk premium. This evidence points to the need to include a control variable to account for risk as an explanatory factor in forecast errors.

There is already a body of research on deviations from rationality in the precious metals market. Aggarwal and Sunderaraghavan (1987) find that changes in silver futures prices are predictable in a markov matrix framework using both the direction and magnitude of price changes. Aggarwal and Lucey (2007) show that psychological barriers exist at round numbers, such as 100's. Cavaletti, Factor and All (2004) discuss the importance of psychological issues in the gold market. Aggarwal and Soenen (1988) show that gold prices have fatter that normal distributions but are weak-form efficient. Lucey and O'Connor (2014) assess whether bubbles occur in the price of gold and find that gold is priced rationally in relation to its lease rates when the variance of the relationship does not 
have to be a constant. Samles (2013) examines the effect of the flow of news into the gold market by classifying news stories into good and bad news. The market is shown to have an asymmetric response to news, with greater reaction to bad news. Further, deviations from rationality are examined by Lucey (2010) who documents large differences in the mean returns of precious metals depending on the stage of the lunar cycle, although they are not statistically significant. This area of study is still in its infancy and warrants further scholarly research.

\section{Data}

We use the London Fixings PM spot gold prices, and 1, 3, 6, and 12 months Gold offer Forward Rate (GOFO) at a daily frequency. Daily data over about a quarter century are examined. Specifically, the daily data runs from the $17^{\text {th }}$ of July 1989 until the end of June 2013. We calculate the forward prices following the market convention of a 360 day year and a 30 day month (LBMA, 2008). Where the delivery date for a forward contract is a non-business day, the value used for delivery is the next good business day as is done in normal trading. This means that at times the delivery price can be constant for 2 or 3 days at a time. As in Aggarwal and Zong (2008), to make our results robust to this fact we estimate all models at a daily frequency corrected to show the market price for delivery on a given day and at a weekly frequency taking the Wednesday value which does not require correction.

Whaley (2000) provides a detailed explanation of the Chicago Board Options Exchange market volatility index (VIX). It measures the expected future volatility over the next 30 calendar days implied by the market using S\&P500 100 index options. This data point gives us a good measure of the level of risk aversion in the market at any given time. We use this data the period of its availability, from 1990 to June 2013. Total ETF gold holdings data were downloaded from Bloomberg and run from November 2004 to June 2013. Below we provide descriptive statistics for gold spot and forward prices, VIX and changes in ETF holdings of gold over our sample at the daily frequency.

\section{[Insert table 1 below]}

Forecast Errors (FE) and Forecast Revisions (FR) are calculated following Aggarwal and Zong (2008) but due to this paper using four forward maturities a slightly different notation is needed. The FE for the 12 month forward rate (FE, $12 \mathrm{~m}$ in table 2 below) is calculated as the difference between the predicted spot rate at $t$ and the realised rate at $t+1\left({ }_{t} F_{t+1}-S_{t+1}\right)$. The $F_{t}$ is the forecast error made in the markets prediction of the spot rate at time $t$, but not observed until $t+1$.

FR's are calculated as the change in the prediction of a future spot price at $t+1$, calculated as follows. At $t-1$ market participants form an expectation of the spot rate at $t$ and $t+1$, which are ${ }_{t-1} F_{t}$ (which is the forward rate, formed at $t-1$, which predicts the spot rate at $t$ ) and ${ }_{t-1} F_{t+1}$ respectively. At $t$ the market revises its expectation of the spot rate for $t+1$ based on new information. The forward rate for $t+1$ then changes and is now expressed as ${ }_{t} F_{t+1}$. The change can be shown as the $F_{t}={ }_{t} F_{t+1} \cdot{ }_{t-1} F_{t+1}$.

For example assume that at $t-1$ the 12 month forward price for gold is $\left.\$ 1500{ }_{t-1} F_{t+1}\right)$ and the 6 month forward price is $\$ 1400\left(t_{t-1} \mathrm{~F}_{t}\right)$. After 6 months the forward price for gold deliverable at $t+1$ is the new 6 month contract $\left({ }_{t} \mathrm{~F}_{t+1}\right)$. This forward price will be different from the original expectation of $\$ 1500$ at $t-$ 1 , say $\$ 1450$ and this represents ${ }_{t} \mathrm{~F}_{\mathrm{t}+1}$. The $\mathrm{FR}$ is then the change in the markets expected price for between $\mathrm{t}-1$ and $\mathrm{t}$ calculated as ${ }_{\mathrm{t}} \mathrm{F}_{\mathrm{t}+1}-{ }_{\mathrm{t}-1} \mathrm{~F}_{\mathrm{t}+1},-\$ 50$ in this case. This $\mathrm{FR}$ is denoted as FR, $12 \mathrm{~m}-6 \mathrm{~m}$ in table 2 below showing descriptive statistics for all FE's and FR's. 
We test for unit roots using Augmented-Dickey Fuller tests with lags selected by the AIC and SCB for all the variables to be examined, with the results presented in Table 3 below for their levels and $1^{\text {st }}$ differences. $* *(* * *)$ represent significance at the 5\% (1\%) levels. As expected, the spot and all forward rates are I(1). All forward premiums, changes in spot exchange rates, FE's, FR's and VIX ${ }^{2}$ are $\mathrm{I}(0)$.

[Insert table 3 about here]

\section{Empirical Analysis}

\subsection{Methods for testing the Forward Rate Unbiasedness Hypothesis}

We test the FRUH in two ways. Firstly we test for cointegration between the forward rate and the future spot rate as in equation 2.3. If $\mathrm{F}_{\mathrm{t}}$ and $\mathrm{S}_{\mathrm{t}+1}$ are cointegrated with a $(1,-1)$ cointegrating vector we have evidence in favour of the FRUH. Zivot (2000) argues that $F_{t}$ and $S_{t}$ also need to be cointegrated with a $(1,-1)$ cointegrating vector. If these relationships are found to exist we have found a long run equilibrium relationship between the two prices, upholding the FRUH.

We also regress the change in the spot rate on the forward premium as in equation 2.4 and test the null hypotheses that $\beta=1, \alpha=0$ and $\mathrm{E}_{\mathrm{t}}\left(\mu_{\mathrm{t}}\right)=0$. If the null hypotheses are rejected, we reject the FRUH. This involves regressing a long horizon dependant variable, the change in the spot rate over 1, 3, 6 and 12 month periods, on an explanatory variable, the change in the spot rate predicted by the forward premium. The dependant variable can therefore suffer from serious autocorrelation. Valkanov (2003) finds that regressions using long horizon returns can have poor statistical power due to the autocorrelation inherent in the data.

This is can be dealt with using the Newey-West (1987) heteroskedasticity and autocorrelation consistent (HAC) standard errors as in Evans and Lyons (2005) who examine exchange rate forecasting. Britten-Jones, Neuberger and Nolte (2011) find that the Newey-West estimator suffers from a downward bias when the forecast horizon is long and the number of observations is small (until about 100 observations). As we have over 6000 daily observations and over 1000 weekly observations this issue not a substantial one here. Testing at the weekly level, where this issue would be less of a factor, should also help to assess whether this is an issue.

Other methods to deal with this problem include Hodrick (1992) who uses a structured covariance estimator generalising the work of Richardson and Smith (1991). Ang and Bekaert (2007) use Hodrick's (1992) correction for long-horizon returns and find that previous methodologies had led to the too frequent rejection of the null hypothesis of forward rate unbiasedness. Autocorrelation can also be dealt with through pre-whitening as in Sul, Philips and Choi (2005). But Britten-Jones et al. (2011) find that these three methods perform equally well.

\subsubsection{Tests of the Forward Rate Unbiasedness Hypothesis}

We begin by testing for cointegration between the forward rate and the spot rate as in the levels equation (2.3) following Johansen (1991), with the results presented below in Table 4. In order for the FRUH to be accepted the $S_{t+1}$ and $F_{t}$, as well as $S_{t}$ and $F_{t}$, must be cointegrated with a $(1,-1)$ cointegrating vector. Table 4 shows that a cointegrating relationship exists between gold spot and 
forward rates at all maturities, but that the cointegrating vector is not $(1,-1)$ for any maturity. This is the case for $\mathrm{S}_{\mathrm{t}+1}$ and $\mathrm{F}_{\mathrm{t}}$ and at a weekly frequency ${ }^{1}$.

\section{[Insert table 4 about here]}

Table 5 shows mixed evidence on the FRUH. At longer horizons the null of FRUH is rejected at the $1 \%$ and 5\% significance levels for daily and mid-week data. However the relationship between spot and forward rates at 1 month conforms to the null of unbiasedness. This long run/short run divide becomes more pronounce at a weekly frequency with 3 and 1 month maturities becoming unbiased.

\section{[Insert table 5 about here]}

Overall the levels and differences methods used to test if the FRUH holds in the gold market seem to suggest it does not hold in the gold market. The cointegration tests are unanimous and the results from the regression analysis suggest that a relationship between spot and forward prices cannot be said to exist with much confidence for the gold forward-spot market as a whole. There is however some evidence that there is predictive power at short horizons.

\subsection{Testing for Behavioural Biases}

\subsubsection{Forecast Errors and Revisions}

Two possible factors that could affect the markets forecast from a behavioural standpoint are that as the market processes new information its general outlook (optimism vs. pessimism) and its response to that information (under vs. over-reaction) are independent of whether the information received is positive or negative.

Forecast Errors (FE's) that tend to be positive reflect general optimism in the market while negative forecast errors show a general pessimism on the part of participants. Optimism can also be found based on the market's reaction to different types of information: if it underreacts to bad information and overreacts to good information. Overreaction occurs when the market's FR's are of the opposite sign to its FE's; i.e., a negative revision is too large and we observe a positive FE. Under-reaction happens when the FR and FE are of the same sign.

All of the dependant variables in equations 4.1-4.6 below are expected to suffer from autocorrelation due to a similar overlapping problem as for the FRUH regression. Consequently, Newey-West heteroskedasticity and autocorrelation consistent (HAC) standard errors are used for all regressions to deal with this with the appropriate number of lags. We also test all models at a weekly frequency. If significant autocorrelation still exists we would expect the $\mathrm{R}^{2 \text { 's }}$ to decline as the frequency is reduced but do not observe a significant reduction for any model.

To control for market risk aversion as a possible explanatory variable for FE's, FR's and the forward premiums in all models in equation 4.1 - 4.5 are tested with and without VIX ${ }^{2}$ (following Banerjee, Doran and Peterson (2007)), but it did not change the results significantly. The COMEX Gold VIX was also considered but as it only exists from 2008 and is highly correlated with VIX (approximately 90\%), and so we employ the broad VIX measure here.

\footnotetext{
${ }^{1}$ Results for weekly data are available from the authors on request.
} 
Following Aggarwal and Zong (2008) we begin by attempting to distinguish between the markets general outlook and the markets strength of response to new information with the equation 4.1a below. It examines the relationship between the markets mistake (the FE) on a particular day and the revisions to its expectations (FR's) on that day.

$$
F E_{t}=\alpha+\beta\left(F R_{t}\right)+\mu_{t}
$$

The null of no behavioural biases is tested by: $\alpha=\beta=0$. A positive alpha points to optimism as when FR's are 0 there is still a FE, while a negative alpha implies pessimism. A positive beta reflects over reaction by the market as the FE and FR are both of the same signs as discussed above and a negative beta shows general under reaction.

Due to data restrictions Aggarwal and Zong (2008) implicitly assume that the relevant FR for any FE is the one with the most similar time period e.g. in our case the FR, $12 \mathrm{~m}-6 \mathrm{~m}$ would be regressed on the FE, $12 \mathrm{~m}$. As we have 4 forward prices rather than 2 we can regress all FR's on each FE and, as in equation $4.1 \mathrm{~b}$ below. This allows us to assess whether relationships exist between different maturities as in equation $4.1 \mathrm{~b}$.

$$
F E_{t}=\alpha+\beta_{1}(F R 12 m 6 m)+\beta_{2}(F R 6 m 3 m)+\beta_{3}(F R 3 m 1 m)+\mu_{t}
$$

[Insert table 6a about here]

Table $6 \mathrm{a}$ shows the results of equations $4.1 \mathrm{a}$ and $4.1 \mathrm{~b}$ using daily data. We see negative and significant constant estimates for all time periods and specifications pointing to pessimism and negative betas indicating under-reaction by the market to news, though they are only significant between the FE, $12 \mathrm{~m}$ and the FR, $12 \mathrm{~m}-6 \mathrm{~m}$. The joint test for no behavioural biases is rejected in all cases at the 5\% significance level for daily data. Weekly data in general agrees, but finds no pessimism or behavioural biases for FE,3m. FR's seem to have some explanatory power at 12 month horizons but no real significance at the shorter horizon as the $\mathrm{R}^{2 \text {, }} \mathrm{s}$ are almost indistinguishable from zero, which is similar to the findings of Aggarwal and Zong (2008).

We now add a control variable for risk aversion in these regressions with the results shown in table $7 \mathrm{~b}$. We find that the constant estimates become universally insignificant at $1 \%$ and $5 \%$ with only 2 significant at $10 \%$, and these two disagree in their signs. For the FE, $12 \mathrm{~m}$ regression $\mathrm{R}^{2}$ increases by almost double though the power of the model is still low at shorter horizons. Evidence is still in favour of behavioural biases at longer horizons but is now firmly rejected at short horizons. This fact is not surprising as at short horizons there was some evidence that the FRUH did hold.

[Insert table $6 \mathrm{~b}$ about here]

$\mathrm{VIX}^{2}$ is negatively related with FE's and significant at all maturities. A negative relationship between FE's and risk aversion implies that as risk aversion rises the market consistently underestimates future spot prices, indicating that speculators are long gold futures contracts. While no explicit data exists on speculative holdings for the forward market, when we look at the Commitment of Traders reports on futures positions from 2006 to 2013 we can see this is the case as in Figure 2 below.

[Insert figure 2 about here] 
We can also examine the stability of our estimates over the period of our sample by running the same regressions on a rolling basis. In Figure 3 we show the evolution of our intercept and slope terms for the regressions with FE, $12 \mathrm{~m}$ with and without our control for risk aversion We begin by running the regressions for 1000 observations and increase the length of the sample up to the full 6000 observations saving the coefficient estimates and their level of significance at each point. When estimates are significant at $1 \%$ they enter a shaded area.

Based on the intercept, without controlling for risk, we see that the market was optimistic until the mid-2000's when it began to change and became pessimistic for the late 2000s and continued to be so over the overall sample. When we control for risk aversion we see that the market switches between moods over the sample period but reflects a more balanced mood over the whole period. The slope estimates that point to systematic under-reaction is relatively consistent with or without the control for risk. The market is characterised by under-reaction for much of the sample; though when we control for risk a short period of significant over-reaction is present in the mid-1990's. The markets risk aversion also changes significantly over the period.

[Insert Figure 3 about here]

\subsection{Past Information and Market Forecasts}

We can also examine how observed changes in the spot price over a prior time period predicts the markets FE which is made at $t$ but not observed until $t+1$.

$$
F E_{t}=\alpha+\beta\left(P S C H_{t-1}\right)+\mu_{t}
$$

Where $\mathrm{PSCH}_{\mathrm{t}-1}$ is the prior period spot rate change $\left(\mathrm{S}_{\mathrm{t}-1}-\mathrm{S}_{\mathrm{t}-2}\right)$ over a given maturity. For a given $\mathrm{FE}$, e.g. FE6m, we assess first how the change in the spot rate over the same period (6 months) that is observed on the prior day effects the markets FE over a 6 month duration (as in Aggarwal and Zong, 2008). This allows us to examine whether the way in which the market incorporates this news causes FE's. If the slope coefficient is negative it indicates over reaction to prior information and vice versa.

We also test equation $4.2 \mathrm{~b}$ to assess if the market is effected by long, medium or short run spot changes in making its predictions, rather than just the same maturity as in equation 4.2a.

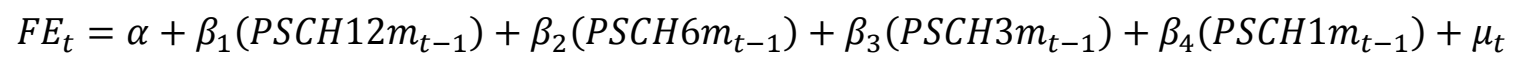

[Insert table $7 \mathrm{a}$ about here]

Table $7 \mathrm{a}$ gives the results of estimating equation $4.2 \mathrm{a}$ and $4.2 \mathrm{~b}$ for daily data. Estimates of the slope coefficient for the 12 month prior spot change $\left(\mathrm{PSCH}_{\mathrm{t}-1} 12 \mathrm{~m}\right)$ are negative and significant for 12 and 6 month FE's, indicating that the market is overreacting to this information to a significant extent in relation to longer run forecasts. This suggests that analysts concentrate on longer run changes in spot rates in making their longer term forecast predictions but at shorter maturities FE's are independent of prior spot changes.

This relationship breaks down at the shortest 1 month forecast horizon. Here only the 1 month prior spot change is significant and a positive beta reflects under-reaction. These findings are replicated at a 
weekly frequency. This finding of under-reaction at short and over-reaction at longer horizons is consistent with Jackson and Johnson (2006).

Including risk as in table $7 \mathrm{~b}$ does not alter the findings above but does change the constant estimates and removes their significance. Without controlling for risk in the model it points to pessimism as before. Including risk once again turns the constant estimates insignificant with negative forecast errors explained through risk aversion rather than behavioural factors. VIX ${ }^{2}$ is significant at all maturities bar 1 month. Allowing for risk aversion increases the adjusted $\mathrm{R}^{2}$ for all models. Figure 4 shows how these coefficients evolve over time. We see again that they are not stable and that the market goes through different moods as time passes. However, since the early 2000's the market has consistently overreacted to prior spot price change information

[Insert table $7 \mathrm{~b}$ about here]

[Insert figure 4 about here]

Easterwood and Nutt (1999) develop the test, originally discussed in Abarbanell and Bernard (1992), to separate out market mood from its reaction to new information. They point out that the overreaction observed may be simply that, or market optimism. If the market overreacts to good information this is optimism. They should then also overreact to good prior information. Therefore, we separate the market's reaction to news from its mood using prior period changes by grouping the prior period spot changes into low, medium and high quartiles. This will allow us to distinguish between reactions of different strengths based on the type of news. We look at the effect of news type on both FE's (as in equation 4.3 below) and the markets forecast, the Forward Premium (FP) in equation 4.4.

$$
\begin{aligned}
& F P_{t}=\alpha+\beta_{1} \text { LoPSCH }_{t-1}+\beta_{2} \text { HiPSCH }_{t-1}+\beta_{3} \text { PSCH }_{t-1}+\beta_{4} \text { DLPSCH }_{t-1}+\beta_{5} \text { DHPSCH }_{t-1}+\mu_{t} \\
& F E_{t}=\alpha+\beta_{1} \text { LoPSCH }_{t-1}+\beta_{2} \text { HiPSCH }_{t-1}+\beta_{3} \text { PSCH }_{t-1}+\beta_{4} \text { DLPSCH }_{t-1}+\beta_{5} \text { DHPSCH }_{t-1}+\mu_{t}
\end{aligned}
$$

Where the $\mathrm{FP}_{\mathrm{t}}={ }_{\mathrm{t}-1} \mathrm{~F}_{\mathrm{t}}-\mathrm{S}_{\mathrm{t}-1,}$, LoPSCH and HiPSCH are dummy variables: HiPSCH is equal to one when $P S C H$ is in the upper quartile for changes and zero when not. $L O P S C H$ is equal to one when PSCH is in the lower quartile for changes and zero when not. DLPSCH and DHPSCH are interactive terms equal to PSCH times LoPSCH and PSCH times HiPSCH respectively.

$\beta_{3}$ in equations 4.3 and 4.4 measures the impact of prior period changes in spot prices on the FP and FE for the average values found in the middle quartiles. To measure the effect of prior spot rate changes in the lower quartile on the predicted change we examine $\beta_{3}+\beta_{4}$, while for the effect of an upper quartile change we add $\beta_{3}+\beta_{5}$. Systematic pessimism exists if we find a significant negative summed coefficient in the lower quartile (overreaction) and a significant positive $\beta_{3}+\beta_{5}$ for the upper quartile. Optimism is found to be present if we reverse the signs on the summed coefficients. This gives us the ability to asses both the attitude and reaction of the markets to new information. We test the null of no behavioural biases as $\beta_{3}+\beta_{4}=0$ and $\beta_{3}+\beta_{5}=0$.

We carry out this regression for all maturities of the FP and FE coupled with all maturities of the PSCH in order to assess whether differing lengths of spot price changes have different effects on the dependant variable at a given maturity. Table 8 presents the results of equation 4.3 coupling each FP 
with each PSCH for all horizons, examining the impact of prior period spot changes on the predicted change in the future spot rate.

\section{[Insert table 8 about here]}

At the daily frequency we find that the sums of $\beta_{3}+\beta_{4}$ and $\beta_{3}+\beta_{5}$ are positive and negative respectively and almost all significantly different from 0 at the 5\% level, indicating systematic optimism. The market underreacts to negative prior period changes in the spot rate, giving a positive sign and overreacts to positive information, with a negative sign. This is consistent across all pairings. The overall explanatory power of the models is small with low $\mathrm{R}^{2 \text {, }}$; as found in Aggarwal and Zong (2008).

Our findings are again very much influenced by when we might have carried out our study. $\beta_{3}+\beta_{4}$ (Bad News) are negative for much of the sample period and our estimates of $\beta_{3}+\beta_{5}$ (Good News) are very volatile. Again a consistent outlook is not apparent over the longer run, and for long periods, like the late 00's the signs on the summer coefficients point to pessimism. Results are similar using weekly data although estimates of $\beta_{3}+\beta_{4}$ are not universally significant. Including risk as an explanatory variable does not have a significant effect on the results presented above and the risk coefficient itself is generally insignificant.

\section{[Insert figure 5 about here]}

[Insert table 9 about here]

Table 9 show the results of estimating equation 4.4. We do not observe any significant optimism or pessimism in the markets assimilation of prior spot changes for FE's. Estimates of the sums of $\beta_{3}+\beta_{4}$ and $\beta_{3}+\beta_{5}$ are generally insignificant. When they are significant the coefficients are positive indicating over-reaction to upper or lower quartile prior spot changes. The middle quartiles' results for $\beta_{3}$ are all negative and significant pointing to under-reaction to average changes. Once again the inclusion of a control for risk aversion as a factor has no material effect on the results. Figure 6 shows the evolution of the summed coefficients when we regress the FEs, $12 \mathrm{~m}$ on the prior year spot change. As in the previous graph we see long periods of pessimism (when $\beta_{3}+\beta_{4}$ is positive and $\beta_{3}+\beta_{5}$ are negative) and unstable coefficients.

[Insert figure 6 about here]

\subsection{Past Information and Forecast Revisions}

Next we examine the effect of prior FE's on the markets FR's, again using upper and lower quartile observations but this time of the markets prior prediction errors, the FE's.

$$
F R_{t}=\alpha+\beta_{1} L o F E_{t-1}+\beta_{2} H i F E_{t-1}+\beta_{3} F E_{t-1}+\beta_{4} D L F E_{t-1}+\beta_{5} D H F E_{t-1}+\mu_{t}
$$

$L o F E_{t-1}$ and $H i F E_{t-1}$ are dummy variables where $H i F E_{t-1}$ is equal to one when $F E_{t-1}$ is in the upper quartile for changes and zero when not. $D L F E_{t-1}$ and $D H F E_{t-1}$ are interactive terms equal to $F E_{t-1}$ times $L o F E_{t-1}$ and $F E_{t-1}$ times $H i F E_{t-1}$ respectively. Under-reaction to information about previous forecast errors in precious metals markets would show as positive slope coefficients and 
negative if over-reaction is the norm. If the markets attitude is generally optimistic then $\beta 3+\beta 4$ should be significant and positive and $\beta 3+\beta 5$ should be negative and significant. We carry out this regression for all maturities of the FR coupled with all maturities of the prior FE.

\section{[Insert table 10 about here]}

Table 10 examines whether prior FE's are explanatory drivers of FR's. The results are that the combined of coefficients for $\beta_{3}+\beta_{4}$ and $\beta_{3}+\beta_{5}$ are always negative for all combinations with all lower quartile estimates FE, $1 \mathrm{~m}$ failing to be significant for longer run FR's. This implies that the market's revisions to its spot price forecasts overreact to the FE's that they observe on the previous day. However we do not observe systematic optimism or pessimism as the reactions is not dependant on the type of information the market receives, it is always an overreaction. The $\mathrm{R}^{2 \text {, }} \mathrm{s}$ are also of a relatively high value indicating good explanatory power. As in the previous models, including risk as a control variable has no material effect.

The relationship between FR's and prior FE's is much more stable than the others examined. While $\beta_{3}+\beta_{4}$ is hovering around zero at times, both summed coefficients are generally negative pointing to a strong systematic bias toward market overreaction to past FE's over the whole period examined.

[Insert figure 7 about here]

\subsection{Role of ETF Flows}

The emergence of Gold ETF's in 2004 created a very visible new source of demand for gold. As shown in Figure 8 ETF gold holdings have increased dramatically since their inception with a peak in their combined stocks of over 84 million ounces in early 2013. Outflows from ETF's since then have coincided with large falls in the gold price raising the possibility that this provides easily accessible information for investors about the general market for gold to use in their decision making. We use this data to assess whether investors mood is affected by learning about changes in total ETF gold holdings.

\section{[Insert Figure 8 about here]}

Information on changes in the gold holdings of ETF's are generally updated the day after trading closes (spdrgoldshares.com) but some funds do report a day or more after that. This means that the information on changes in how much gold is held by ETF's is assimilated by the market in London on the day after the change in ETF holdings actually occurs. For this study we examined 67 ETF's reported gold holdings on a daily basis. This data was corrected so that it reflected information coming to the market. Most funds gold holdings were delayed by one day to reflect the lag in information that could affect GOFO or the PM fixing.

As in previous sections we use upper and lower quartile observations of changes in ETF gold holdings to assess the effect on the markets prediction errors, the FE's as in equation 4.6.

$$
F E_{t}=\alpha+\beta_{1} \operatorname{LocETF}_{t-1}+\beta_{2} \operatorname{HicETF}_{t-1}+\beta_{3} c \operatorname{ETF}_{t-1}+\beta_{4} \operatorname{DLCETF}_{t-1}+\beta_{5} \text { DHcETF }_{t-1}+\mu_{t}
$$


Where $\mathrm{cETF}_{\mathrm{t}-1}$ is the change in aggregate reported holdings of gold by all ETF's on the evening before GOFO is set and the PM gold fixing occurs. LocETF $F_{t-1}$ is a dummy variable which equal 1 when $\mathrm{cETF}_{\mathrm{t}-1}$ is in the upper quartile for changes and zero when not. DLcETF $\mathrm{t}_{-1}$ and $\mathrm{DHcETF}_{\mathrm{t}-1}$ are interactive terms equal to $\mathrm{cETF}_{\mathrm{t}-1}$ times $\mathrm{LocETF}_{\mathrm{t}-1}$ and $\mathrm{cETF}_{\mathrm{t}-1}$ times HicETF $\mathrm{t}_{\mathrm{t}-1}$ respectively. Underreaction to information about changes in ETF holdings by precious metals markets would show as positive slope coefficients and negative if over-reaction is the norm. If the markets attitude is generally optimistic then $\beta 3+\beta 4$ should be significant and positive and $\beta 3+\beta 5$ should be negative and significant. We carry out this regression for all maturities of the FE as in equation 4.6 and finally the same regression with the $\mathrm{FR}_{\mathrm{t}}$ as the dependant variable.

\section{[Insert table 11 about here]}

The results for the effect of ETF flows are that the combined slope coefficients are negative at the 12, 6 and 3 month maturities. Only large outflows (lower quartile changes) of gold from the ETF's (the low estimates) have a statistically significant effect on the markets forecast errors, normal flows and large inflows seem to be discounted by the market. This points to market under-reaction to large outflows of gold in the ETF data over the sample. The upper and lower quartile ETF flows have no significant effect on the markets forecast revisions while the average reaction is to consistently overreact to this type of information. This shorter time horizon gives stable estimates of the coefficients given in table 4.9 under a rolling analysis as in previous sections.

\subsection{Economic significance}

Table 12 shows the economic significance of the intercept and slope coefficient estimations made in the earlier sections. We do this for the first estimation from each of the previous tables to give indications as to the economic size of the coefficient estimates. For regressions where dummy variables are used, we take the central (normal) estimate to assess the economic significance of the model. We assess the significance of each estimated coefficient by forcing it to take a value of zero. This simulated estimate is then compared with the estimate where no restrictions were placed on alpha or beta. The mean FE12m, FR12m,6m, FR12m, VIX ${ }^{2}$, PSCH12m and Change in ETF holdings used are as reported in section 3 .

From equation $4.1 \mathrm{~b}$ we can see that using FR's has a very large impact on the estimation of the FE. The prior spot change also has a significant impact as measured through equation $4.2 \mathrm{~b}$. Using VIX ${ }^{2}$ consistently changes the estimate of FE by $40 \%$ in both equations $4.1 \mathrm{~b}$ and $4.2 \mathrm{~b}$. Despite the beta estimated for the PSCH in equation 4.3 being highly statistically significant it appears to be much less economically significant causing only a 7\% change in the FP when it is dropped. The estimated betas in equations 4.4 and 4.5 also have highly significant impacts, while dropping the coefficient on change in ETF holdings from equation 4.6 causes a $23 \%$ change in the estimated FR. Some estimates alphas also have large economic effects such as in equations $4.1 \mathrm{~b}, 4.3$ and 4.6.

[Insert table 12 about here]

\section{Conclusion}

This paper examines rationality in the largest precious metals (gold) market. We document that the gold forward and spot markets in general do not conform to rational expectations especially at horizons longer that a month (there is some evidence in favour at the 1 month horizon). The forward price is generally not an unbiased predictor of the future spot price. 
Drawing on the earlier work of Easterwood and Nutt (1999) and Aggarwal and Zong (2008), we examine two possible reasons for these deviations from rationality, risk aversion and behavioural factors. Based on these models, we examine optimism, pessimism, under-reaction, and over-reaction in the gold forward market. The findings documented and discussed here are established as economically significant in most cases.

The gold market's Forecast Errors are generally found to be pessimistic. However, as expected, when we control for risk aversion using VIX ${ }^{2}$, we see a fall in Forecast Errors when volatility rises, indicating that speculators are long gold futures contracts. This is partially confirmed by Commitments on Trader's data from the Commodities Futures Trading Commission. Further, when we allow for differing reactions to positive and negative prior information we fail to find optimism or pessimism. Forecast Errors in the gold market are only affected by large gold outflows in ETF holdings, but under-react to this news. In fact, the market's mood and reaction to information has not been a constant over time. The market's Forward Premiums overreacting to all news in the late 1990's and being pessimistic in the mid-2000's. However, Forward Premiums over the full sample are found to be optimistic, overreacting to good information and under-reacting to bad. This model also has the highest explanatory power indicating that prior Forecast Errors are a major driver of the markets Forecast Revisions.

However, we find strong evidence that over the full sample period the gold market overreacts to prior spot price changes. The market's Forecast Revisions are fairly stable with overreaction dominating over the almost the whole period examined.

In summary, in this paper we document that gold forward markets do not conform to rational expectations. In general, they over-react and are optimistic. These deviations from rationality are systematic, economically significant, and not explained by plausible other economic factors such as market risk or ETF gold demand. Behavioural factors are clearly shown to be important in the gold forward markets. 


\section{References}

Abarbanell, J. and Bernard, V. (1992) Tests of analysts' overreaction and underreaction to earnings information as an explanation for anomalous stock price behaviour. Journal of Finance 47: 1181-1207.

Aggarwal, R. (2004) Persistent puzzles in international finance and economics. The Economic and Social Review 35(3): 241-250.

Aggarwal, R. and Lucey B. (2007) Psychological barriers in gold prices? Review of Financial Economics 16: 217-30.

Aggarwal, R., S. Mohanty, and F. Song (1995) Are Survey Forecasts of Macroeconomic Variables Rational? Journal of Business 68 (1): 99-119.

Aggarwal, R. and L. Soenen (1988) Nature and Efficiency of the Gold Market. Journal of Portfolio Management 14 (3): 18-21.

Aggarwal, R. and Sundararaghavan, P. (1987) Efficiency of the Silver Futures Market: An Empirical Study Using Daily Data. Journal of Banking and Finance 11 (1): 49-64.

Aggarwal, R. and Zong, S. (2008) Behavioral Biases in Forward Rates as Forecasts of Future Exchange Rates: Evidence of Systematic Pessimism and Under-Reaction. Multinational Finance Journal 12(3): 241-277.

Amir, E., and Ganzach, Y. (1998) Overreaction and under reaction in analyst's forecast. Journal of Economic Behavior and Organization 37(3): 333-347.

Ang, A. and G. Bekaert (2007), Stock Return Predictability: Is it There? Review of Financial Studies 20(3): 651-707.

Ball, L. and Croushore, D. (2001) How do forecasts respond to changes in monetary policy? Business Review 4: 9-16.

Baillie, R. (1989) Econometric tests of rationality and market efficiency. Econometric Reviews 8(2): 151-186.

Banerjee, P., Doran, J. and Peterson, D. (2007) Implied volatility and future portfolio returns. Journal of Banking \& Finance 31: 3183-3199

Britten-Jones, Neuberger and Nolte (2012) Improved Inference in Regression with Overlapping Observations. Journal of Business Finance \& Accounting, 38(5): 657-683.

Cavaletti, C., Factor, T. and All, D. (2004) Will gold hold its luster? Futures, 33: 24-31.

Daniel, K., Hirshleifer, D. and Subrahmanyam, A. (1998) Investor psychology and security market under- and overreactions. Journal of Finance 53, 1839-1885.

DeBondt, W. and Thaler, R. (1990) Do security analysts overreact? American Economic Review 80: $52-57$.

Easterwood, J. and Nutt, S. (1999) Inefficiency in analysts' earnings forecasts: systematic misreaction or systematic optimism? The Journal of Finance 54(5): 1777-1797.

Elliott, J., Philbrick, D. and Wiedman, C. (1995) Evidence from archival data on the relation between security analysts' forecast errors and prior forecast revisions. Contemporary Accounting Research 11: 919-938.

Engel, C. (1992) The forward discount anomaly and the risk premium: A survey of recent evidence. Journal of empirical finance 3(2): 123-192.

Evans, M. and Lyons, R. (2005) Redux: Micro-based exchange rate forecasting. CRIF Seminar series.

Frankel, J. and Rose, A. (1994) A Survey of empirical research on nominal exchange rates. National Bureau of Economic Research, Working Paper No. 4865.

Froot, K. and Thaler, R. (1990) Anomalies: foreign exchange. The Journal of Economic Perspectives 4(3): 179-192.

Gospodinov, N. (2009) A new look at the forward premium puzzle. Journal of Financial Econometrics 7(3): 312-338.

$\mathrm{Gu}, \mathrm{Z}$. and Xue, J. (2007) Do analysts overreact to extreme good news in earnings? Review of Quantitative Finance and Accounting 29(4): 415-431.

Gurkaynak, R. and Wolfers, J. (2006) Macroeconomic derivatives: An initial analysis of market-based macro forecasts, uncertainty, and risk. National Bureau of Economic Research, No. 11929. 
Hakkio, C. and Rush, M. (1989) Market efficiency and cointegration: An application to the sterling and deutschemark exchange markets. Journal of International Money and Finance 8: 75-88.

Hicks, R. Value and Capital. (1939) Oxford: Clarendon Press.

Hodrick, R. (1992) Dividend Yields and Expected Stock Returns: Alternative Procedures for

Inference and Measurement. Review of Financial Studies 5( 3): 357-86.

Jackson, A., and Johnson, T. (2006) Unifying underreaction anomalies. Journal of Business 79(1): 75-114.

Johansen, S. (1991) Estimation and Hypothesis Testing of Cointegration Vectors in Gaussian Vector Autoregressive Models. Econometrica 59(6): 1551-1580.

Kang, S., O'Brien, J. and Sivaramakrishnan, K. (1994) Analysts' interim earnings forecasts: Evidence on the forecasting process. Journal of Accounting Research 32: 103-112.

Kolb, R. (1992) Is normal backwardation normal?" Journal of Futures Markets 12(1): 75-91

Keynes, J. (1930) A Treatise on Money. London: Macmillan.

Kirtzman, M. (1993) Optimal Currency Hedging Policy with Biased Forward Rates. Journal of Portfolio Management. 19(4): 94-101.

LBMA (London Bullion Market Association) (2008). A Guide to the London Precious Metals Markets. Published by: The London Bullion Market Association and the London Platinum and Palladium Market.

Lewis, K. (1989) Can learning affect exchange-rate behavior? The case of the dollar in the early 1980's. Journal of Monetary Economics 23(1): 79-100.

Lucey, B. (2010) Lunar seasonality in precious metal returns? Applied Economics Letters 17:835838.

Lucey, B., Larkin, C., and O'Connor, F. (2013). New York or London : Where and when does the gold price originate? Applied Economics Letters. 20:813-817.

Lucey, B. and O'Connor, F. (2014) Do Bubbles occur in Gold Prices? Evidence from Gold Lease Rates and Markov Switching Models. Borsa Istanbul Review (forthcoming)

MacDonald, R. and Taylor, M. (1989) Foreign exchange market efficiency and cointegration: Some evidence from the recent float. Economics Letters 29(1):63-68.

MacDonald, R. and Taylor, M. eds.(1992) Exchange rate economics. Chapter 15.

Mohanram, Partha, and Dan Gode. "Removing predictable analyst forecast errors to improve implied cost of equity estimates." Review of Accounting Studies (2013): 1-36.

Murray, S. (2011) Loco London Liquidity Survey. The Alchemist 63, 9-10.

Newey, W. and West, K. (1987), A Simple, Positive Semi-Definite, Heteroskedasticity and

Autocorrelation Consistent Covariance Matrix. Econometrica 55: 703-8.

Richardson, M. and T. Smith (1991) Tests of Financial Models in the Presence of Overlapping Observations. Review of Financial Studies 4(2): 227-54.

Smales, Lee A., News Sentiment in the Gold Futures Market (2013). Available at SSRN: http://ssrn.com/abstract=2309868

http://www.spdrgoldshares.com/usa/historical-data/

Sul, D., Phillips, P. and Choi, C. (2005) Prewhitening Bias in HAC Estimation. Oxford Bulletin of Economics and Statistics 67(4): 517-546.

Valkanov, R. (2003), Long-horizon Regressions: Theoretical Results and Applications. Journal of Financial Economics 68(2): 201-32.

Whaley, R. (2000) The investor fear gauge. The Journal of Portfolio Management 26(3): 12-17.

Zivot, E. (2000) Cointegration and forward and spot exchange rate regressions. Journal of International Money and Finance 19(6): 785-812. 
Table 1: Descriptive statistics for gold daily data

\begin{tabular}{|l|ccccccc|}
\hline & PM Spot & $\begin{array}{c}\text { 1 Month } \\
\text { Gold }\end{array}$ & $\begin{array}{c}\text { 3 Month } \\
\text { Gold }\end{array}$ & $\begin{array}{c}\text { 6 Month } \\
\text { Gold }\end{array}$ & $\begin{array}{c}\text { 12 Month } \\
\text { Gold }\end{array}$ & VIX & $\begin{array}{c}\text { Change in } \\
\text { ETF Holdings }\end{array}$ \\
\hline Mean & 590.34 & 591.47 & 593.51 & 596.93 & 604.08 & 20.294 & 25.29763 \\
ST. Dev & 400.23 & 400.01 & 400.09 & 400.24 & 399.56 & 8.079 & 189.5209 \\
Skewness & 1.722 & 1.718 & 1.717 & 1.71 & 1.694 & 1.998 & 1.888 \\
Kurtosis & 1.824 & 1.811 & 1.813 & 1.797 & 1.747 & 7.064 & 22.63 \\
\hline Obs. & 6250 & 6250 & 6250 & 6250 & 6250 & 6134 & 2291 \\
\hline
\end{tabular}

Table 2: Descriptive statistics for Forecast Errors and Revisions

\begin{tabular}{|c|c|c|c|c|c|c|c|}
\hline & $\begin{array}{l}\text { FE, } \\
12 \mathrm{~m}\end{array}$ & FR, 12m-6m & FE, $6 \mathrm{~m}$ & FR, 6m-3m & FE, 3m & $\begin{array}{c}\text { FR, 3m- } \\
\text { 1m }\end{array}$ & FE, 1m \\
\hline Mean & -38.26 & -17.77 & -17.26 & -8.32 & -7.58 & -5.53 & -2.20 \\
\hline ST. Dev & 116.5 & 80.86 & 83.460 & 57.718 & 60.45 & 50.307 & 38.00 \\
\hline Skewness & -1.399 & -0.657 & -0.353 & -0.677 & -0.2362 & -0.872 & 0.1671 \\
\hline Kurtosis & 2.857 & 4.618 & 5.669 & 6.228 & 7.167 & 8.437 & 9.102 \\
\hline Obs. & 5997 & 6103 & 6125 & 6168 & 6190 & 6189 & 6233 \\
\hline
\end{tabular}

Table 3: Unit Root Tests

\begin{tabular}{|c|c|c|}
\hline & Level & $I^{\text {st }}$ Difference \\
\hline Spot Rate & 2.96461 & $-19.5981 * * *$ \\
\hline VIX $^{2}$ & $-9.61134 * * *$ & - \\
\hline Forward: 1m & 2.90844 & $-37.0326 * * *$ \\
\hline Forward: $\mathbf{2 m}$ & 2.35541 & $-27.1167 * * *$ \\
\hline Forward: 3m & 2.99609 & $-35.4100 * * *$ \\
\hline Forward: $6 \mathrm{~m}$ & 3.01068 & $-35.1164 * * *$ \\
\hline $\begin{array}{l}\text { Forward: } \\
\text { 12m }\end{array}$ & 2.61212 & $-35.7437 * * *$ \\
\hline FP: $1 \mathrm{~m}$ & $-28.1523 * * *$ & - \\
\hline FP: $2 m$ & $-19.7006^{* * *}$ & - \\
\hline FP: 3m & $-17.7254 * * *$ & - \\
\hline FP: $6 \mathrm{~m}$ & $-17.6420 * * *$ & - \\
\hline FP: $12 \mathrm{~m}$ & $-13.4304 * * *$ & - \\
\hline $\mathbf{S}_{3}-\mathbf{S}_{\mathbf{1}}$ & $-7.76657 * * *$ & - \\
\hline $\mathbf{S}_{6}-\mathbf{S}_{1}$ & $-4.94034 * * *$ & - \\
\hline$S_{12}-S_{1}$ & $-3.22574 * * *$ & - \\
\hline FE, 12m & $-3.51976 * * *$ & - \\
\hline FR, 12m-6m & $-5.50996 * * *$ & - \\
\hline FE, 6m & $-4.84832 * * *$ & - \\
\hline FR, 6m-3m & $-10.9656 * * *$ & - \\
\hline FE, 3m & $-7.81184 * * *$ & - \\
\hline FR, 3m-1m & $-15.4564 * * *$ & - \\
\hline
\end{tabular}


Table 4: Testing for Johansen Cointegration between $S_{t+1}$ and $F_{t}$ (Daily Data)

\begin{tabular}{|c|c|c|c|c|c|c|}
\hline & $\begin{array}{c}\text { Eigenvalu } \\
\mathrm{e}\end{array}$ & Trace & $\begin{array}{c}5 \% \text { Critical } \\
\text { Value } \\
\end{array}$ & P-Value & $\mathbf{r}$ & $(1,-1)$ \\
\hline \multirow[t]{2}{*}{$S_{t+12 m}$ Vs. 12m Forward } & 0.008 & 49.297 & 25.731 & 0.000 & 0 & \\
\hline & 0.001 & 4.014 & 12.448 & 0.739 & 1 & No \\
\hline \multirow[t]{2}{*}{$S_{t+6 m}$ Vs. 6m Forward } & 0.007 & 47.721 & 25.731 & 0.000 & 0 & \\
\hline & 0.001 & 4.199 & 12.448 & 0.714 & 1 & No \\
\hline \multirow[t]{2}{*}{$S_{t+4 m}$ Vs. 3m Forward } & 0.016 & 100.690 & 25.731 & 0.000 & 0 & \\
\hline & 0.003 & 3.589 & 12.448 & 0.795 & 1 & No \\
\hline \multirow[t]{2}{*}{$S_{t+1 m}$ Vs. 1m Forward } & 0.155 & 1048.08 & 25.731 & 0.000 & 0 & \\
\hline & 0.001 & 3.406 & 12.448 & 0.818 & 1 & No \\
\hline
\end{tabular}

Table 5: Differences test for FRUH

\begin{tabular}{|l|ccc|}
\hline & $\boldsymbol{\alpha}$ & $\boldsymbol{\beta}$ & Null \\
\cline { 2 - 4 } S Vs. F: 12m & $45.44[0.133]$ & $0.526[0.674]$ & 0.135 \\
S Vs. F: 6m & 30.27 & 1.127 & \\
& $25.20[0.035]$ & $-0.191[0.064]$ & 0.091 \\
S Vs. F: 3m & 11.95 & 0.645 & \\
& $10.81[0.066]$ & $-0.002[0.041]$ & 0.100 \\
S Vs. F: 1m & 5.884 & 0.491 & \\
& $3.425[0.064]$ & $-0.083[0.000]$ & 0.000 \\
& 1.855 & 0.141 & \\
\hline
\end{tabular}

Note: We test equation 2.4 using OLS with Newey-West HAC standard errors, showing $\alpha$ and $\beta$ as the coefficient estimates. Standard errors are given in italics below the coefficients. $P$-values for the null hypotheses $(\beta=1, \alpha=0)$ are given in parenthesis next to the coefficient estimate. $P$-values for jointly testing the null of $\beta=1, \alpha=0$ are given in the null column. Maximum lag length set $\left.=4(t / 2100)^{2 / 9}\right)$ as suggested by Newey and West (1987). 
Table 6a: Test for behavioural biases, Daily

\begin{tabular}{|l|cccc|cc|}
\hline $\begin{array}{l}\text { Dependant } \\
\text { Variable }\end{array}$ & $\mathbf{A}$ & FR,12M-6M & FR,6M-3M & FR,3M-1M & $\mathbf{R}^{2}$ & Null \\
\hline FE, $12 \mathrm{~m}$ & $-30.793 * * *$ & $-0.429 * * *$ & & & 0.075 & 0.000 \\
& 4.625 & 0.119 & & & & \\
& $-30.741 * * *$ & $-0.482 * * *$ & 0.032 & 0.104 & 0.076 & 0.000 \\
& 4.631 & 0.140 & 0.215 & 0.231 & & \\
\hline FE,6m & $-16.541 * * *$ & & -0.059 & & 0.001 & 0.000 \\
& 3.404 & & 0.096 & & & \\
& $-16.19 * * *$ & -0.095 & 0.041 & -0.018 & 0.005 & \\
& 2.971 & 0.114 & 0.185 & 0.151 & & \\
\hline FE,3m & $-7.267 * * *$ & & & -0.033 & 0.000 & 0.009 \\
& 2.481 & & & 0.112 & & \\
& $-5.868 * *$ & -0.106 & 0.035 & 0.024 & 0.010 & 0.0335 \\
& 2.520 & 0.065 & 0.102 & 0.102 & & \\
\hline
\end{tabular}

Note: SE's are given below the coefficient estimates in italics with ***, **, and * indicating significance at 1\%, 5\% and 10\% level. All regressions use Newey-West HAC standard errors.

Table 6b: Test for behavioural biases, Daily with Risk

\begin{tabular}{|l|cccc|c|cc|}
\hline $\begin{array}{l}\text { Dependant } \\
\text { Variable }\end{array}$ & $\boldsymbol{\alpha}$ & FR,12M-6M & FR,6M-3M & FR,3M-1M & VIX $^{2}$ & $\mathbf{R}^{\mathbf{2}}$ & Null \\
\hline FE,12m & -4.013 & $-0.439 * * *$ & & & $-0.054^{* * *}$ & 0.126 & 0.000 \\
& 6.684 & 0.122 & & & 0.012 & & \\
& -3.481 & $-0.513^{* * *}$ & 0.047 & 0.143 & $-0.055^{* * *}$ & 0.129 & 0.0004 \\
& 6.417 & 0.135 & 0.191 & 0.217 & 0.011 & & \\
\hline FE,6m & $-7.312^{*}$ & & -0.062 & & $-0.020^{* * *}$ & 0.015 & 0.198 \\
& 4.417 & & 0.097 & & .007 & & \\
& -6.085 & -0.104 & 0.042 & -0.006 & $-0.020^{* * *}$ & 0.019 & 0.482 \\
& 4.075 & 0.114 & 0.184 & 0.150 & 0.006 & & \\
\hline FE,3m & 0.890 & & & -0.028 & $-0.016^{* * *}$ & 0.018 & 0.924 \\
& 3.778 & & & 0.086 & 0.006 & & \\
& $2.658 *$ & -0.114 & 0.038 & 0.036 & $-0.017 * * *$ & 0.030 & 0.470 \\
& 3.851 & 0.064 & 0.099 & 0.100 & 0.006 & & \\
\hline
\end{tabular}

Note: SE's are given below the coefficient estimates in italics with ***,**, and * indicating significance at 1\%, 5\% and $10 \%$ level. All regressions use Newey-West HAC standard errors. 
Table 7a: Prior Spot rate change as a determinant of forecast error, Daily data

\begin{tabular}{|c|c|c|c|c|c|c|}
\hline $\begin{array}{l}\text { Dependant } \\
\text { Variable }\end{array}$ & A & $\begin{array}{c}\mathrm{PSCH}_{\mathrm{t}-} \\
{ }_{1} 12 \mathrm{~m}\end{array}$ & $\mathbf{P S C H}_{\mathrm{t}-1} 6 \mathrm{~m}$ & $\mathbf{P S C H}_{\mathrm{t}-1} \mathbf{3 m}$ & $\mathrm{PSCH}_{\mathrm{t}-1} \mathbf{1 m}$ & $\mathbf{R}^{2}$ \\
\hline \multirow[t]{4}{*}{ FE12m } & $-22.046 * * *$ & $-0.338 * * *$ & & & & 0.096 \\
\hline & 4.472 & 0.075 & & & & \\
\hline & $-21.97 * * *$ & $-0.276^{* * *}$ & -0.182 & 0.002 & $0.363^{*}$ & 0.108 \\
\hline & 4.311 & 0.096 & 0.183 & 0.203 & 0.220 & \\
\hline \multirow[t]{4}{*}{ FE6m } & $-15.85^{* * *}$ & & -0.072 & & & 0.004 \\
\hline & 2.899 & & 0.0717 & & & \\
\hline & $-9.319 * * *$ & $-0.290 * * *$ & 0.228 & -0.010 & 0.148 & 0.068 \\
\hline & 2.925 & 0.075 & 0.148 & 0.175 & 0.153 & \\
\hline \multirow[t]{4}{*}{ FE3m } & $-6.736 * * *$ & & & -0.048 & & 0.001 \\
\hline & 2.577 & & & 0.076 & & \\
\hline & -3.447 & $-0.101 *$ & 0.024 & -0.017 & 0.139 & 0.043 \\
\hline & 2.418 & 0.060 & 0.107 & 0.102 & 0.113 & \\
\hline \multirow[t]{4}{*}{ FE1m } & $-2.700 * *$ & & & & $0.124 * *$ & 0.019 \\
\hline & 1.380 & & & & 0.070 & \\
\hline & -1.062 & -0.015 & -0.030 & -0.043 & $0.207 * * *$ & 0.037 \\
\hline & 1.366 & 0.032 & 0.055 & 0.064 & 0.069 & \\
\hline
\end{tabular}

Note: SE's are given below the coefficient estimates in italics with ***, **, and * indicating significance at 1\%, 5\% and $10 \%$ level. All regressions use Newey-West HAC standard errors.

Table 7b: Prior Spot rate change as a determinant of forecast error, Daily data with risk

\begin{tabular}{|c|c|c|c|c|c|c|c|}
\hline $\begin{array}{l}\text { Dependant } \\
\text { Variable }\end{array}$ & $\alpha$ & $\begin{array}{c}\mathrm{PSCH}_{\mathrm{t}-} \\
{ }_{1} 12 \mathrm{~m}\end{array}$ & $\operatorname{PSCH}_{t-1} 6 m$ & $\begin{array}{c}\mathbf{P S C H}_{\mathrm{t}-} \\
{ }_{13} \mathbf{m}\end{array}$ & $\mathrm{PSCH}_{\mathrm{t}-1} 1 \mathrm{~m}$ & $\mathbf{V i x}^{2}$ & $\mathbf{R}^{2}$ \\
\hline \multirow[t]{2}{*}{ FE12m } & 2.690 & $-0.325^{* * *}$ & & & & $-0.051 * * *$ & 0.143 \\
\hline & 6.793 & 0.078 & & & & 0.010 & \\
\hline \multirow[t]{2}{*}{ FE12m } & 3.921 & $-0.263 * * *$ & -0.222 & 0.0294 & $0.375^{*}$ & $-0.053 * * *$ & 0.143 \\
\hline & 6.606 & 0.088 & 0.165 & 0.198 & 0.217 & 0.011 & \\
\hline \multirow[t]{4}{*}{ FE6m } & -5.866 & & -0.074 & & & $-0.020 * * *$ & 0.017 \\
\hline & 4.084 & & 0.072 & & & 0.006 & \\
\hline & -0.264 & $-0.284 * * *$ & 0.215 & -0.004 & 0.152 & $-0.018 * * *$ & 0.080 \\
\hline & 4.016 & 0.073 & 0.146 & 0.177 & 0.155 & 0.005 & \\
\hline \multirow[t]{4}{*}{ FE3m } & 1.327 & & & -0.047 & & $-0.016 * * *$ & 0.019 \\
\hline & 3.858 & & & 0.076 & & 0.006 & \\
\hline & 4.623 & $-0.096^{*}$ & 0.012 & -0.009 & 0.142 & $-0.016^{* * *}$ & 0.044 \\
\hline & 3.858 & 0.059 & 0.104 & 0.102 & 0.115 & 0.006 & \\
\hline \multirow[t]{4}{*}{ FE1m } & -1.137 & & & & $0.125^{*}$ & -0.003 & 0.016 \\
\hline & 2.162 & & & & 0.069 & 0.004 & \\
\hline & 0.339 & -0.014 & -0.031 & -0.041 & $0.208 * *$ & -0.002 & 0.033 \\
\hline & 2.383 & 0.031 & 0.055 & 0.065 & 0.069 & 0.004 & \\
\hline
\end{tabular}

Note: SE's are given below the coefficient estimates in italics with ***,**, and * indicating significance at 1\%, 5\% and $10 \%$ level. All regressions use Newey-West HAC standard errors. 
Table 8: Determinants of the Forward Premium, Daily

\begin{tabular}{|c|c|c|c|c|c|c|c|c|}
\hline \multirow{2}{*}{$\begin{array}{c}\text { Dependant } \\
\text { Variable }\end{array}$} & \multirow{2}{*}{ PSCH } & \multicolumn{2}{|c|}{ Low } & \multicolumn{2}{|c|}{ Normal } & \multicolumn{2}{|c|}{ High } & \multirow[b]{2}{*}{$\mathbf{R}^{2}$} \\
\hline & & $\alpha$ & $\boldsymbol{\beta}$ & $\alpha$ & $\boldsymbol{\beta}$ & $\alpha$ & $\boldsymbol{\beta}$ & \\
\hline \multirow[t]{6}{*}{ FP12m } & \multirow[t]{2}{*}{$12 \mathrm{~m}$} & 13.322 & 0.049 & 14.100 & -0.063 & 25.370 & -0.043 & 0.073 \\
\hline & & 0.000 & 0.000 & 0.000 & 0.000 & 0.000 & 0.000 & \\
\hline & \multirow[t]{2}{*}{$6 \mathrm{~m}$} & 15.549 & 0.040 & 13.125 & -0.020 & 18.800 & -0.031 & 0.026 \\
\hline & & 0.000 & 0.000 & 0.000 & 0.365 & 0.000 & 0.025 & \\
\hline & \multirow[t]{2}{*}{$3 \mathrm{~m}$} & 15.783 & 0.054 & 13.350 & -0.090 & 18.020 & -0.034 & 0.029 \\
\hline & & 0.000 & 0.000 & 0.000 & 0.002 & 0.000 & 0.035 & \\
\hline \multirow[t]{6}{*}{ FP 6m } & \multirow[t]{2}{*}{$12 \mathrm{~m}$} & 6.354 & 0.018 & 6.888 & -0.041 & 14.247 & -0.031 & 0.040 \\
\hline & & 0.000 & 0.059 & 0.000 & 0.000 & 0.000 & 0.000 & \\
\hline & \multirow[t]{2}{*}{$6 \mathrm{~m}$} & 7.327 & 0.016 & 6.429 & -0.017 & 11.220 & -0.033 & 0.020 \\
\hline & & 0.000 & 0.033 & 0.000 & 0.137 & 0.000 & 0.009 & \\
\hline & \multirow[t]{2}{*}{$3 m$} & 7.652 & 0.025 & 6.550 & -0.043 & 10.783 & -0.048 & 0.027 \\
\hline & & 0.000 & 0.012 & 0.000 & 0.012 & 0.000 & 0.001 & \\
\hline \multirow[t]{6}{*}{ FP $3 \mathrm{~m}$} & \multirow[t]{2}{*}{$12 \mathrm{~m}$} & 3.213 & 0.013 & 3.390 & -0.019 & 6.723 & -0.015 & 0.020 \\
\hline & & 0.000 & 0.003 & 0.000 & 0.000 & 0.000 & 0.000 & \\
\hline & \multirow[t]{2}{*}{$6 \mathrm{~m}$} & 3.800 & 0.012 & 3.198 & -0.010 & 4.680 & -0.012 & 0.009 \\
\hline & & 0.000 & 0.000 & 0.000 & 0.118 & 0.000 & 0.026 & \\
\hline & \multirow[t]{2}{*}{$3 \mathrm{~m}$} & 3.786 & 0.016 & 3.244 & -0.023 & 4.490 & -0.016 & 0.009 \\
\hline & & 0.000 & 0.000 & 0.000 & 0.016 & 0.000 & 0.013 & \\
\hline
\end{tabular}

Note: P-values' are given below the coefficient estimates in italics. All regressions use Newey-West HAC standard errors.

Table 9: Determinants of FE, Daily

\begin{tabular}{|c|c|c|c|c|c|c|c|c|}
\hline \multirow{2}{*}{$\begin{array}{c}\text { Dependant } \\
\text { Variable }\end{array}$} & \multirow{2}{*}{ PSCH } & \multicolumn{2}{|c|}{ Low } & \multicolumn{2}{|c|}{ Normal } & \multicolumn{2}{|c|}{ High } & \multirow[b]{2}{*}{$\mathbf{R}^{2}$} \\
\hline & & $\alpha$ & $\beta$ & $\alpha$ & $\beta$ & $\alpha$ & $\beta$ & \\
\hline \multirow[t]{6}{*}{ FE $12 \mathrm{~m}$} & \multirow[t]{2}{*}{$12 \mathrm{~m}$} & 6.837 & 0.247 & -2.168 & -1.079 & -131.548 & 0.090 & 0.149 \\
\hline & & 0.551 & 0.511 & 0.564 & 0.000 & 0.000 & 0.441 & \\
\hline & \multirow[t]{2}{*}{$6 \mathrm{~m}$} & 27.882 & 0.809 & -7.439 & -1.034 & -154.212 & 0.254 & 0.189 \\
\hline & & 0.006 & 0.022 & 0.015 & 0.000 & 0.000 & 0.104 & \\
\hline & \multirow[t]{2}{*}{$3 \mathrm{~m}$} & -10.659 & 0.316 & -15.260 & -1.730 & -94.471 & 0.058 & 0.076 \\
\hline & & 0.335 & 0.379 & 0.000 & 0.000 & 0.000 & 0.798 & \\
\hline \multirow[t]{6}{*}{ FE 6m } & \multirow[t]{2}{*}{$12 \mathrm{~m}$} & -3.946 & -0.154 & 1.999 & -0.694 & 60.939 & 0.031 & 0.070 \\
\hline & & 0.462 & 0.295 & 0.441 & 0.000 & 0.000 & 0.701 & \\
\hline & \multirow[t]{2}{*}{$6 \mathrm{~m}$} & 20.969 & 0.801 & -4.137 & -0.539 & -56.740 & 0.123 & 0.064 \\
\hline & & 0.000 & 0.000 & 0.033 & 0.000 & 0.000 & 0.258 & \\
\hline & \multirow[t]{2}{*}{$3 \mathrm{~m}$} & -4.785 & 0.247 & -8.377 & -0.787 & -48.570 & 0.204 & 0.022 \\
\hline & & 0.459 & 0.279 & 0.000 & 0.000 & 0.000 & 0.103 & \\
\hline FE 3m & $12 \mathrm{~m}$ & 0.820 & -0.131 & 1.283 & -0.296 & -53.847 & 0.119 & 0.057 \\
\hline
\end{tabular}




\begin{tabular}{|c|c|cc|cc|cc|c|} 
& \multirow{3}{*}{$6 \mathrm{~m}$} & 0.923 & 0.605 & 0.403 & 0.000 & 0.000 & 0.038 & \\
& -1.532 & 0.011 & -1.726 & -0.076 & -38.112 & 0.121 & 0.025 \\
& 0.811 & 0.964 & 0.211 & 0.348 & 0.000 & 0.120 & \\
& \multirow{3}{*}{$3 \mathrm{~m}$} & -3.879 & -0.047 & -2.794 & -0.369 & -35.270 & 0.203 & 0.022 \\
& 0.470 & 0.801 & 0.052 & 0.001 & 0.000 & 0.031 & \\
\hline
\end{tabular}

Note: P-values' are given below the coefficient estimates in italics. All regressions use Newey-West HAC standard errors. 
Table 10: Determinants of forecast revision (OLS) Daily

\begin{tabular}{|c|c|c|c|c|c|c|c|c|}
\hline \multirow{2}{*}{$\begin{array}{l}\text { Dependant } \\
\text { Variable }\end{array}$} & \multirow[b]{2}{*}{$F E_{t-1}$} & \multicolumn{2}{|c|}{ Low } & \multicolumn{2}{|c|}{ Normal } & \multicolumn{2}{|c|}{ High } & \multirow[b]{2}{*}{$\mathbf{R}^{2}$} \\
\hline & & $\alpha$ & $\beta$ & $\alpha$ & $\beta$ & $\alpha$ & $\beta$ & \\
\hline \multirow[t]{8}{*}{ FR12m6m } & $12 \mathrm{~m}$ & -22.686 & -0.593 & 2.222 & -0.434 & 30.382 & -1.082 & 0.600 \\
\hline & & 0.053 & 0.000 & 0.227 & 0.000 & 0.000 & 0.000 & \\
\hline & $6 m$ & 4.408 & -0.951 & -0.565 & -1.020 & -0.697 & -1.009 & 0.964 \\
\hline & & 0.015 & 0.000 & 0.005 & 0.000 & 0.291 & 0.000 & \\
\hline & $3 m$ & 14.468 & -1.037 & 0.592 & -1.170 & 11.162 & -0.839 & 0.553 \\
\hline & & 0.035 & 0.000 & 0.692 & 0.094 & 0.000 & 0.000 & \\
\hline & $1 \mathrm{~m}$ & 12.090 & -1.433 & -2.160 & -1.100 & 9.570 & -0.268 & 0.302 \\
\hline & & 0.098 & 0.000 & 0.183 & 0.000 & 0.261 & 0.423 & \\
\hline \multirow[t]{8}{*}{ FR6m3m } & $12 \mathrm{~m}$ & -26.087 & -0.362 & 1.233 & -0.213 & 19.843 & -0.617 & 0.334 \\
\hline & & 0.038 & 0.000 & 0.379 & 0.000 & 0.146 & 0.000 & \\
\hline & $6 m$ & -14.886 & -0.590 & -0.086 & -0.404 & 7.554 & -0.636 & 0.532 \\
\hline & & 0.069 & 0.000 & 0.927 & 0.000 & 0.003 & 0.000 & \\
\hline & $3 m$ & 0.843 & -0.960 & -0.013 & -1.004 & -1.317 & -0.949 & 0.942 \\
\hline & & 0.399 & 0.000 & 0.939 & 0.000 & 0.083 & 0.000 & \\
\hline & $1 \mathrm{~m}$ & 4.938 & -1.076 & -1.969 & -0.946 & 2.266 & -0.516 & 0.349 \\
\hline & & 0.363 & 0.000 & 0.060 & 0.000 & 0.715 & 0.041 & \\
\hline \multirow[t]{8}{*}{$\mathrm{FR} 3 \mathrm{~m} 1 \mathrm{~m}$} & $12 \mathrm{~m}$ & -29.445 & -0.309 & 0.435 & -0.153 & 18.145 & -0.508 & 0.262 \\
\hline & & 0.025 & 0.000 & 0.727 & 0.000 & 0.093 & 0.015 & \\
\hline & $6 m$ & -22.686 & -0.493 & -0.986 & -0.285 & 12.484 & -0.518 & 0.373 \\
\hline & & 0.022 & 0.000 & 0.319 & 0.000 & 0.000 & 0.000 & \\
\hline & $3 m$ & -11.155 & -0.779 & -1.025 & -0.654 & -0.232 & -0.580 & 0.578 \\
\hline & & 0.026 & 0.000 & 0.197 & 0.000 & 0.942 & 0.000 & \\
\hline & $1 \mathrm{~m}$ & 2.092 & -1.023 & -0.961 & -0.963 & -3.193 & -0.589 & 0.440 \\
\hline & & 0.698 & 0.000 & 0.22 & 0.000 & 0.339 & 0.000 & \\
\hline
\end{tabular}

Note: P-values' are given below the coefficient estimates in italics. All regressions use Newey-West HAC standard errors. 
Table 11: Forecast Errors, Forecast Revisions and ETF flows (OLS) Daily

\begin{tabular}{|c|c|c|c|c|c|c|c|}
\hline $\begin{array}{l}\text { Dependant } \\
\text { Variable }\end{array}$ & $\begin{array}{l}\text { Low } \\
\alpha\end{array}$ & $\boldsymbol{\beta}$ & $\begin{array}{l}\text { Normal } \\
\alpha\end{array}$ & $\boldsymbol{\beta}$ & $\begin{array}{l}\text { High } \\
\alpha\end{array}$ & $\boldsymbol{\beta}$ & $\mathbf{R}^{2}$ \\
\hline FE12m & $\begin{array}{r}-137.000 \\
0.000\end{array}$ & $\begin{array}{r}-0.144 \\
0.018\end{array}$ & $\begin{array}{r}-111.300 \\
0.000\end{array}$ & $\begin{array}{r}-0.027 \\
0.932\end{array}$ & $\begin{array}{r}-102.700 \\
0.000\end{array}$ & $\begin{array}{r}-0.013 \\
0.655\end{array}$ & 0.026 \\
\hline FE6m & $\begin{array}{r}-45.863 \\
0.000\end{array}$ & $\begin{array}{r}-0.012 \\
0.032\end{array}$ & $\begin{array}{r}-48.784 \\
0.000\end{array}$ & $\begin{array}{r}-0.089 \\
0.758\end{array}$ & $\begin{array}{r}-52.060 \\
0.009\end{array}$ & $\begin{array}{r}-0.132 \\
0.566\end{array}$ & 0.022 \\
\hline FE3m & $\begin{array}{r}-1.027 \\
0.929\end{array}$ & $\begin{array}{r}-0.111 \\
0.010\end{array}$ & $\begin{array}{r}-18.699 \\
0.000\end{array}$ & $\begin{array}{r}-0.202 \\
0.285\end{array}$ & $\begin{array}{r}-26.444 \\
0.004\end{array}$ & $\begin{array}{r}-0.007 \\
0.756\end{array}$ & 0.061 \\
\hline FE1m & $\begin{array}{l}0.063 \\
0.993\end{array}$ & $\begin{array}{l}0.007 \\
0.117\end{array}$ & $\begin{array}{r}-5.437 \\
0.196\end{array}$ & $\begin{array}{r}-0.235 \\
0.024\end{array}$ & $\begin{array}{r}-0.108 \\
0.110\end{array}$ & $\begin{array}{r}-0.040 \\
0.633\end{array}$ & 0.017 \\
\hline FR12m6m & $\begin{array}{r}63.539 \\
0.000\end{array}$ & $\begin{array}{l}0.068 \\
0.167\end{array}$ & $\begin{array}{r}55.797 \\
0.000\end{array}$ & $\begin{array}{l}0.649 \\
0.005\end{array}$ & $\begin{array}{r}68.873 \\
0.000\end{array}$ & $\begin{array}{r}-0.015 \\
0.704\end{array}$ & 0.012 \\
\hline FR6m3m & $\begin{array}{r}18.495 \\
0.090\end{array}$ & $\begin{array}{l}0.054 \\
0.119\end{array}$ & $\begin{array}{r}21.264 \\
0.000\end{array}$ & $\begin{array}{l}0.322 \\
0.005\end{array}$ & $\begin{array}{r}36.322 \\
0.000\end{array}$ & $\begin{array}{r}-0.004 \\
0.884\end{array}$ & 0.012 \\
\hline $\mathrm{FR} 3 \mathrm{~m} 1 \mathrm{~m}$ & $\begin{array}{r}12.792 \\
0.155\end{array}$ & $\begin{array}{l}0.080 \\
0.000\end{array}$ & $\begin{array}{r}11.795 \\
0.000\end{array}$ & $\begin{array}{l}0.156 \\
0.005\end{array}$ & $\begin{array}{r}22.957 \\
0.006\end{array}$ & $\begin{array}{r}-0.002 \\
0.952\end{array}$ & 0.019 \\
\hline
\end{tabular}

Note: P-values' are given below the coefficient estimates in italics. All regressions use Newey-West HAC standard errors. 
Table 12: Sample of the Economic Significance of Estimates

\begin{tabular}{|c|c|c|c|c|c|c|c|c|c|c|c|c|}
\hline \multicolumn{6}{|c|}{ Average Values and Model Estimates of the Coefficients } & \multirow{2}{*}{$\begin{array}{c}\text { Average } \\
\text { estimate (7) }\end{array}$} & \multicolumn{6}{|c|}{ Economic Significance of Estimates } \\
\hline (1) & $(2)$ & (3) & (4) & (5) & (6) & & (8) & $(9)$ & $(\mathbf{1 0})^{\circ}$ & (11) & (12) & (13) \\
\hline Equ 4.1b & $\overline{F R} 12 \mathrm{~m} 6 \mathrm{~m}$ & $\overline{\operatorname{Vix} x^{2}}$ & $\alpha$ & $\boldsymbol{\beta}(\mathbf{F R})$ & $\beta\left(\mathbf{V I X}^{2}\right)$ & Est. of FE & $\beta(\mathbf{F R})=\mathbf{0}$ & Change & $\alpha=\mathbf{0}$ & Change & $\beta(\mathbf{V i x})=0$ & Change \\
\hline FE,12m & -17.77 & 20.294 & -4.01 & -0.439 & -0.054 & 2.692 & -5.108 & $290 \%$ & 6.705 & $149 \%$ & 1.596 & $41 \%$ \\
\hline Equ 4.2b & $\overline{P S C H 12 m}$ & $\overline{V \iota x^{2}}$ & $\alpha$ & $\boldsymbol{\beta}(\mathrm{PSCH})$ & $\beta\left(\mathrm{VIX}^{2}\right)$ & Est. of FE & $\begin{array}{l}\beta(\mathrm{PSCH})= \\
0\end{array}$ & Change & $\alpha=\mathbf{0}$ & Change & $\beta($ Vix $)=0$ & Change \\
\hline FE,12m & 52.37 & 20.294 & 2.69 & -0.325 & -0.51 & -24.680 & -7.650 & $69 \%$ & -27.370 & $11 \%$ & -35.030 & $42 \%$ \\
\hline Equ 4.3 & $\overline{P S C H 12 m}$ & & $\alpha$ & $\boldsymbol{\beta}(\mathrm{PSCH})$ & & Est of FP & $\begin{array}{l}\beta(\operatorname{PSCH})= \\
0\end{array}$ & Change & $\alpha=\mathbf{0}$ & Change & & \\
\hline FP, 12m & 13.82 & & 14.1 & -0.063 & & 13.229 & 14.100 & $7 \%$ & -0.870 & $107 \%$ & & \\
\hline Equ 4.4 & $\overline{P S C H 12 m}$ & & $\alpha$ & $\boldsymbol{\beta}(\mathrm{PSCH})$ & & Est of FE & $\begin{array}{l}\boldsymbol{\beta}(\mathrm{PSCH})= \\
0\end{array}$ & Change & $\alpha=0$ & Change & & \\
\hline FE,12m & 52.37 & & -2.16 & -1.079 & & -58.675 & -2.168 & $96 \%$ & -56.507 & $4 \%$ & & \\
\hline Equ 4.5 & $\overline{F E 12 m}$ & & $\alpha$ & $\beta(\mathbf{F E})$ & & Est of FR & $\beta(F E)=0$ & Change & $\alpha=0$ & Change & & \\
\hline FR12m,6m & -38.26 & & 2.22 & -0.434 & & 18.826 & 2.222 & $88 \%$ & 16.604 & $12 \%$ & & \\
\hline Equ 4.6 & $\overline{\overline{c E T F}}$ & & $\alpha$ & B(ETF) & & Est of FR & $\beta(E T F)=0$ & Change & $\alpha=0$ & Change & & \\
\hline FR12m,6m & 25.297 & & 55.7 & 0.649 & & 72.214 & 55.797 & $23 \%$ & 16.417 & $77 \%$ & & \\
\hline
\end{tabular}

$\overline{F E 12 m}, \overline{P S C H 12 m}, \overline{c E T F}, \overline{V l x^{2}}$ and $\overline{\overline{F R} 12 \mathrm{~m} 6 \mathrm{~m}}$ are the means of the: 12 month forecast error, prior 12 month spot price change, daily change in ETF gold holdings, VIX ${ }^{2}$ and forecast revision between 12 and 6 months. Estimates of alphas and betas are from the regression indicated in column (1). The average estimates given in column (7) are found using the averages from column (2) and (3) and the estimates of alpha and betas given in columns (4), (5) and (6). Columns (8), (10) and (12) report the estimates with one coefficient held to zero. Columns (9), (11) and (13) report the change of estimate with a zero imposed coefficient. 
Figure 1: 12 Month Gold Forward Premium

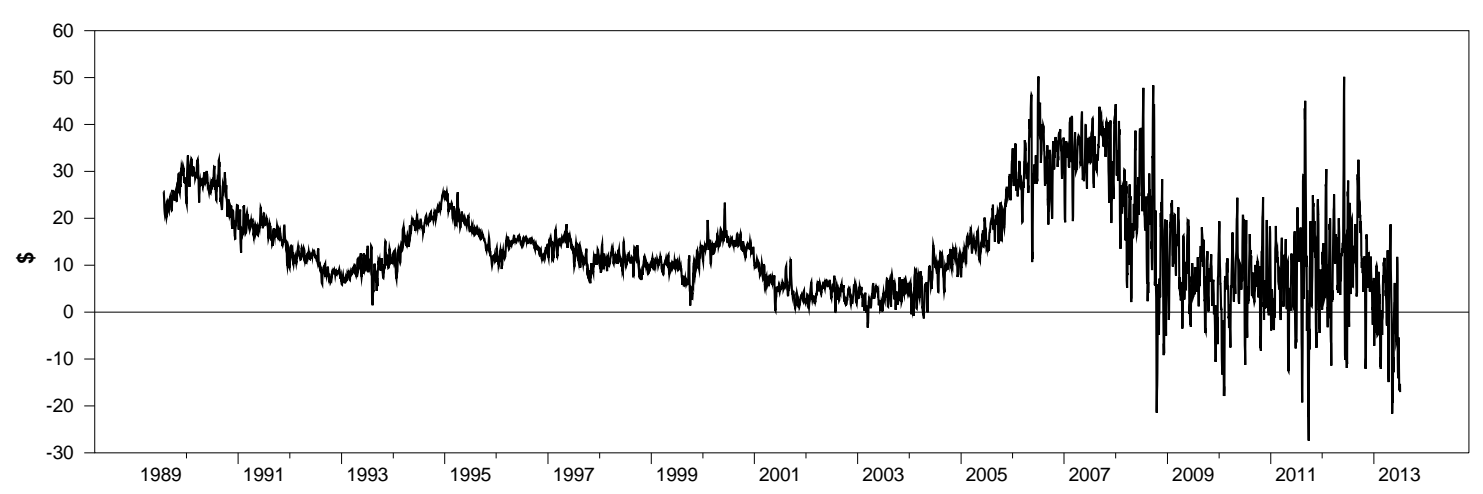

Figure 2: Producers and Speculators Futures Positions, No. of Contracts held

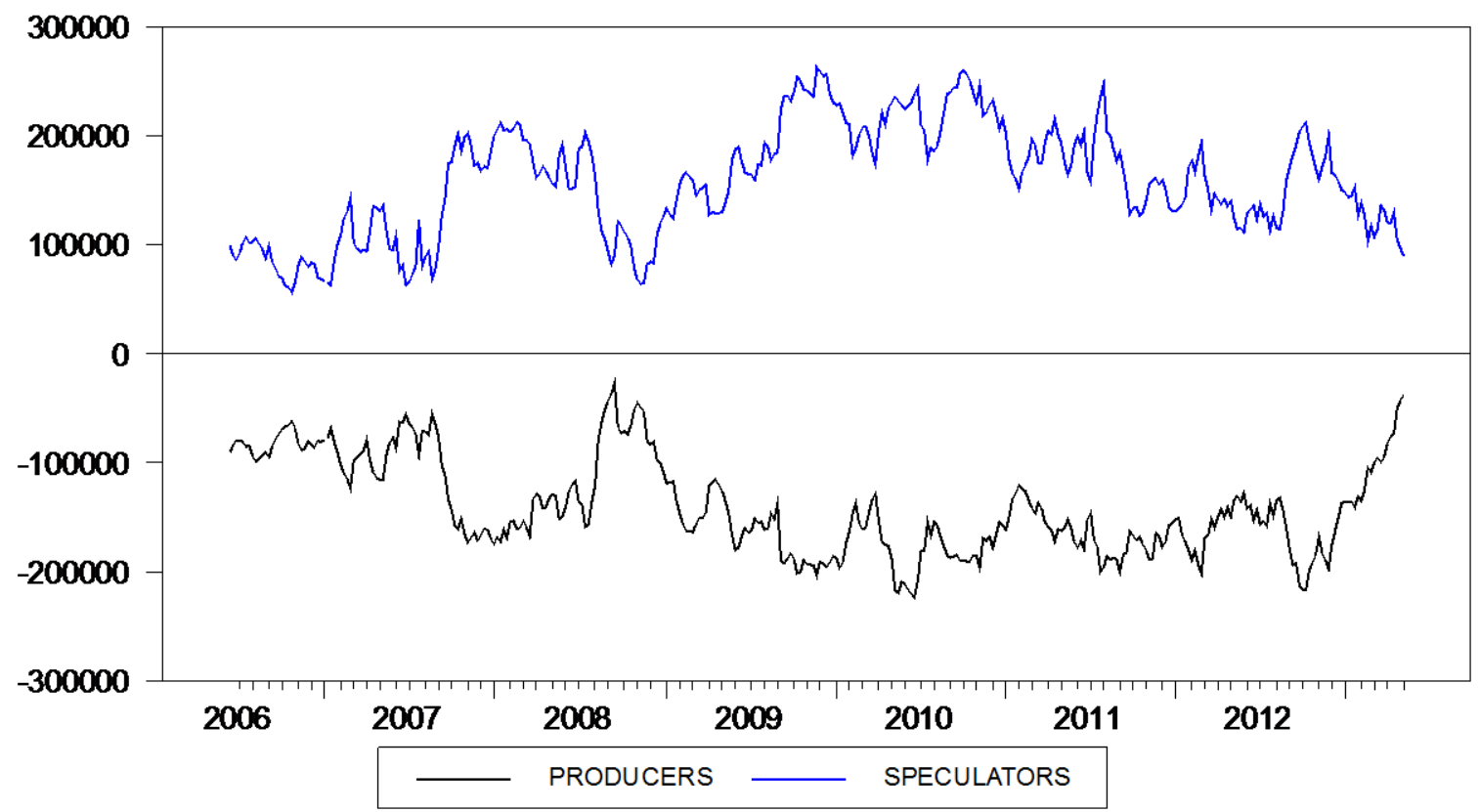

Source: Commodities Futures Treading Commission (http://www.cftc.gov)

Figure 3: Evolution of Coefficients 12 month Horizon, Equation 4.1a

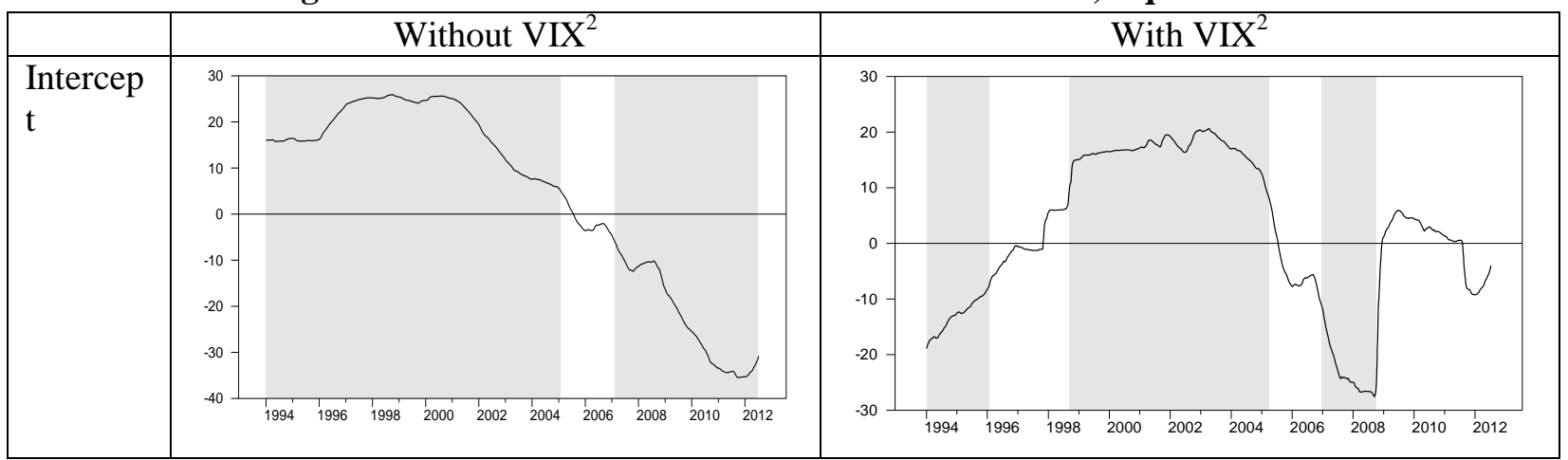




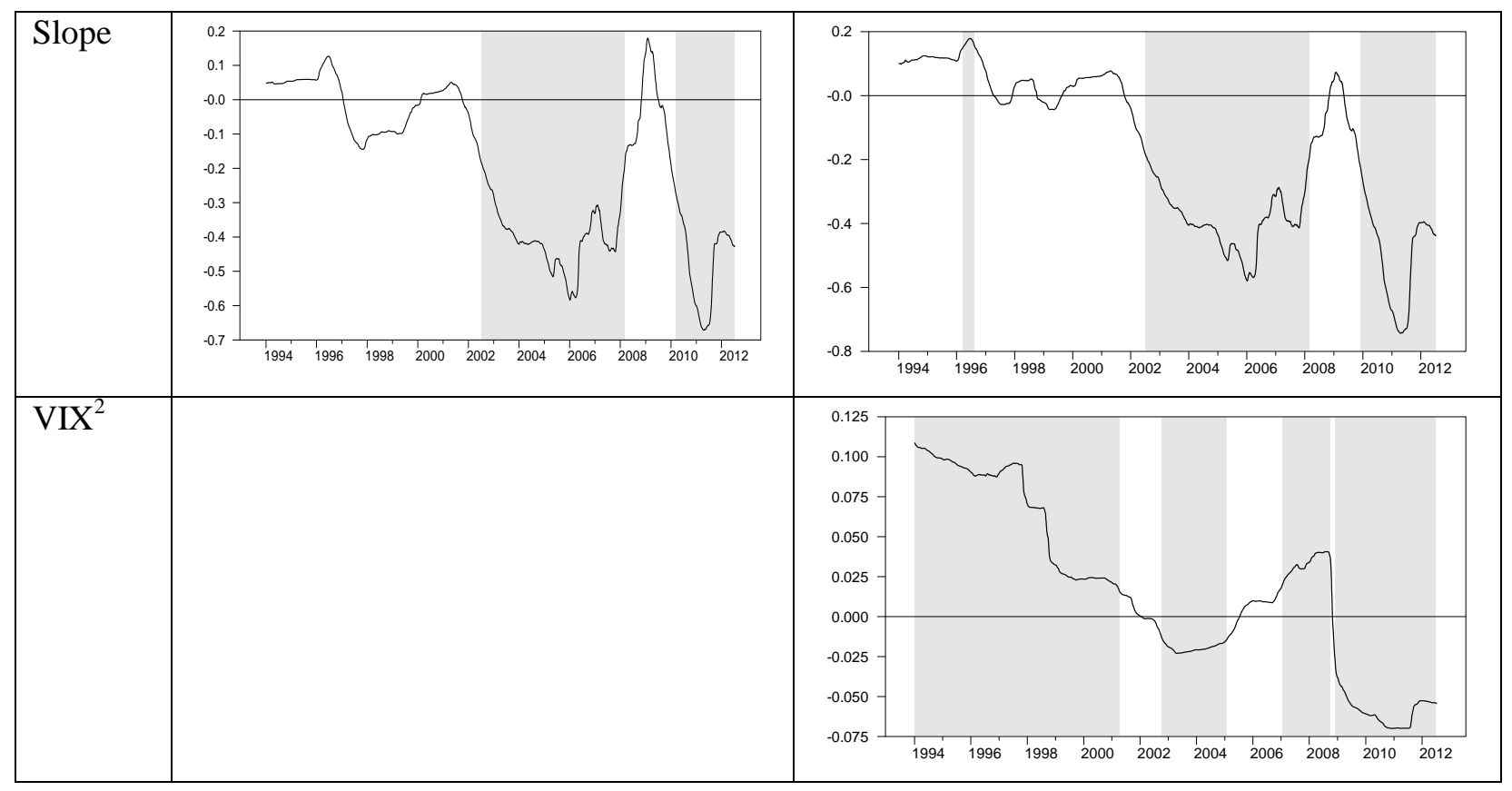

Figure 4: Evolution of Coefficients 12 Month Horizon, equations 4.4a

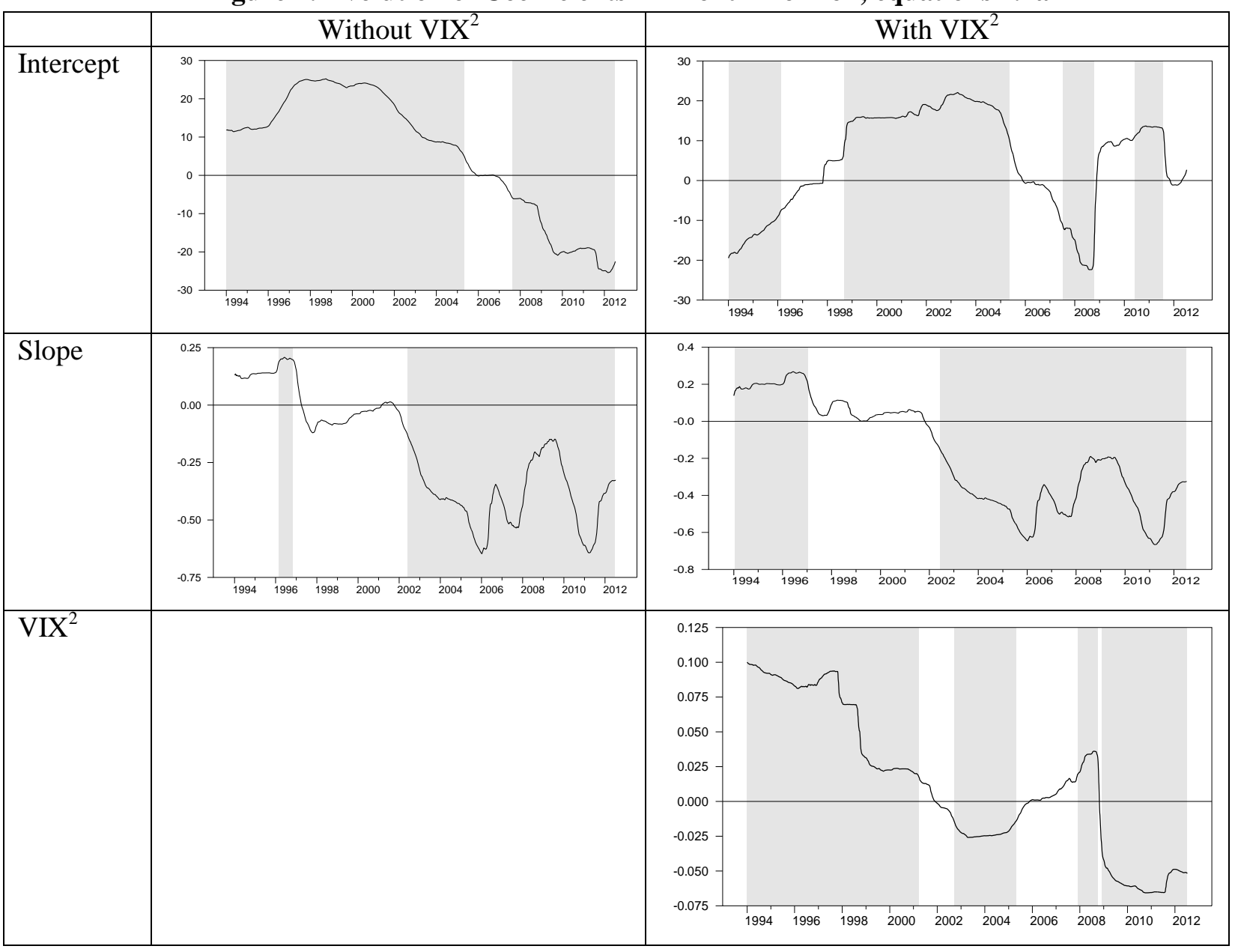


Figure 5: Evolution of Coefficients (FP, 12m PSCH 12m), equation 4.3

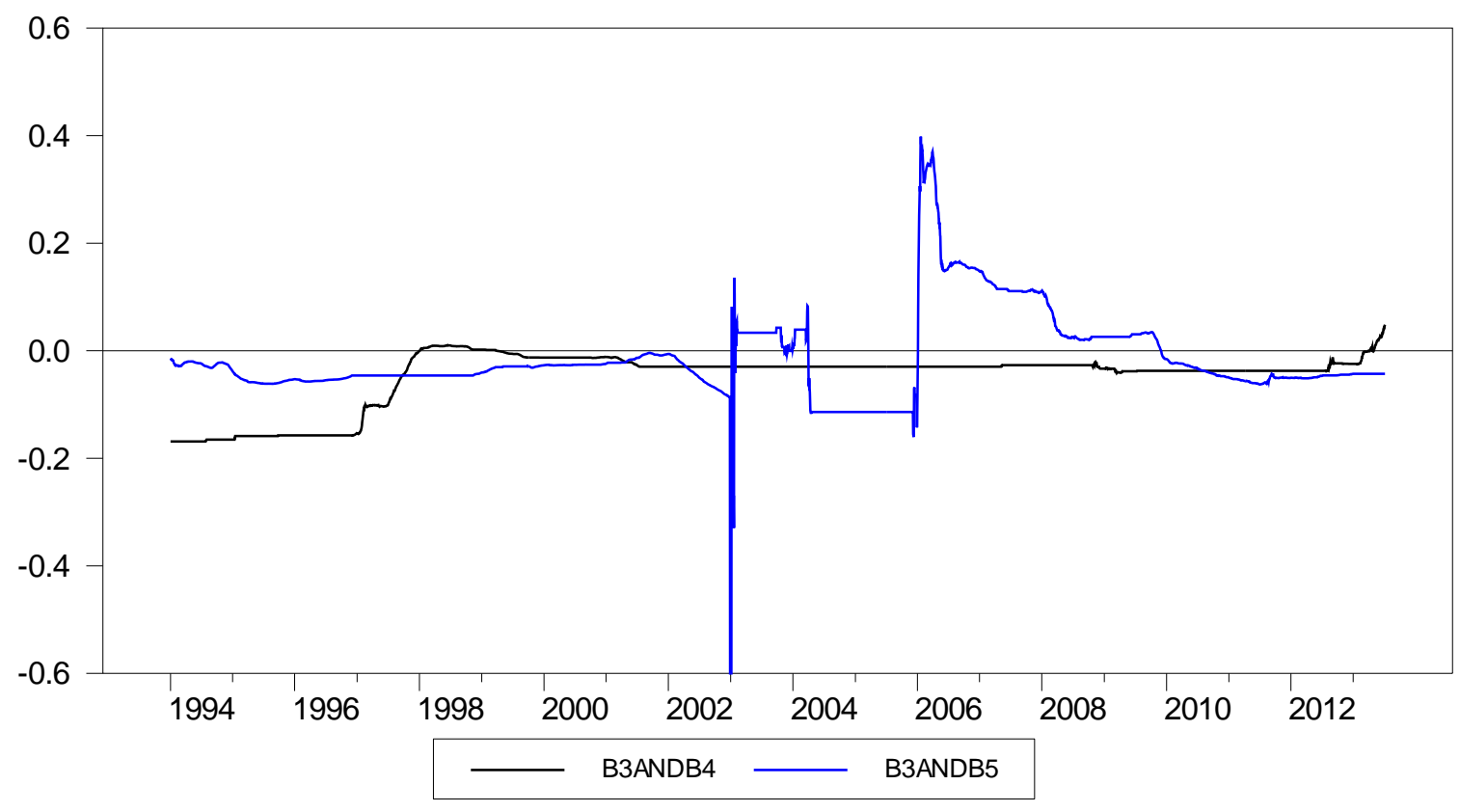

Figure 6: Evolution of Coefficients (FE, 12m PSCH 12m), equation 4.4

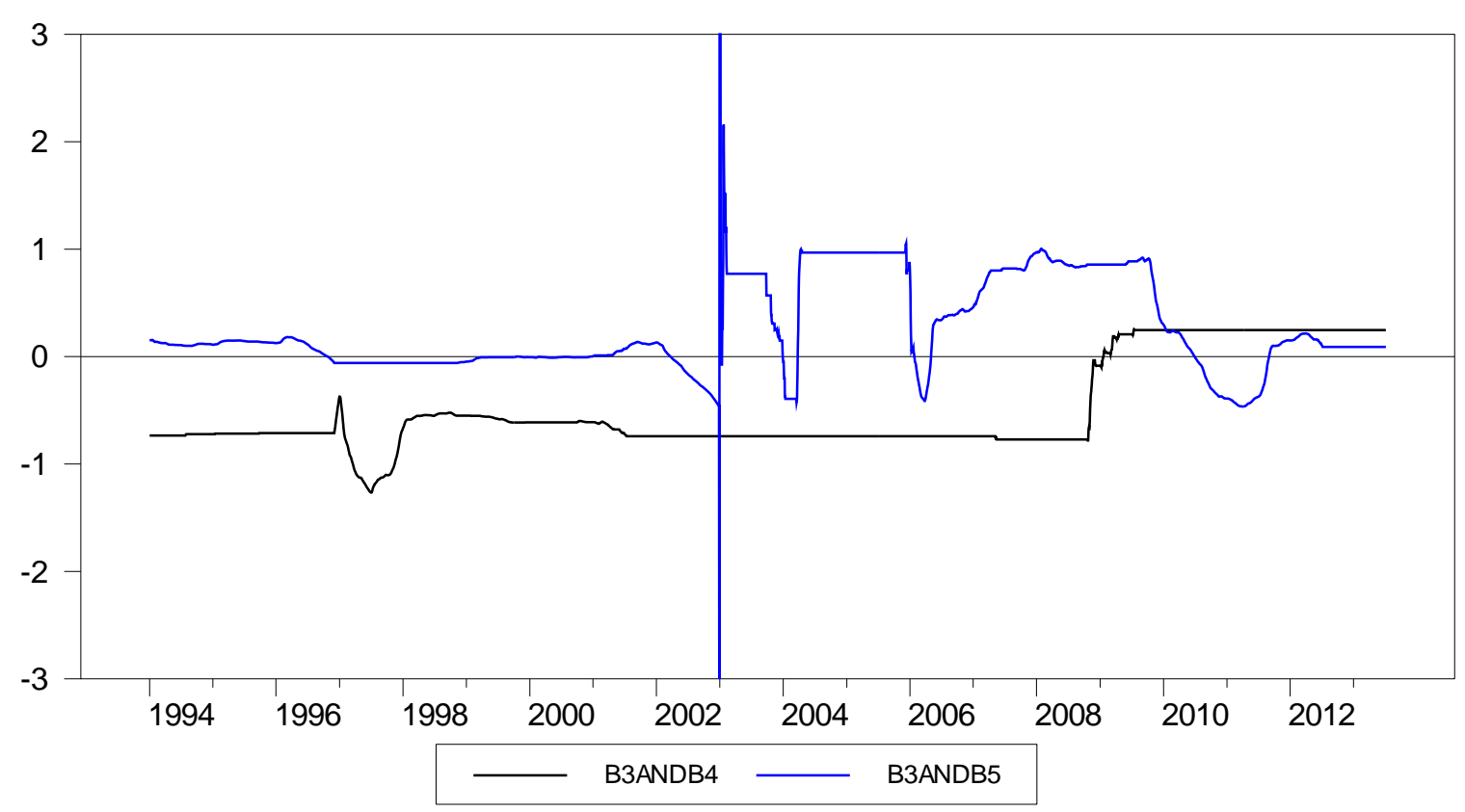


Figure 7: Evolution of Coefficients (FR, 12m-6m, FE, 12m), equation 4.7

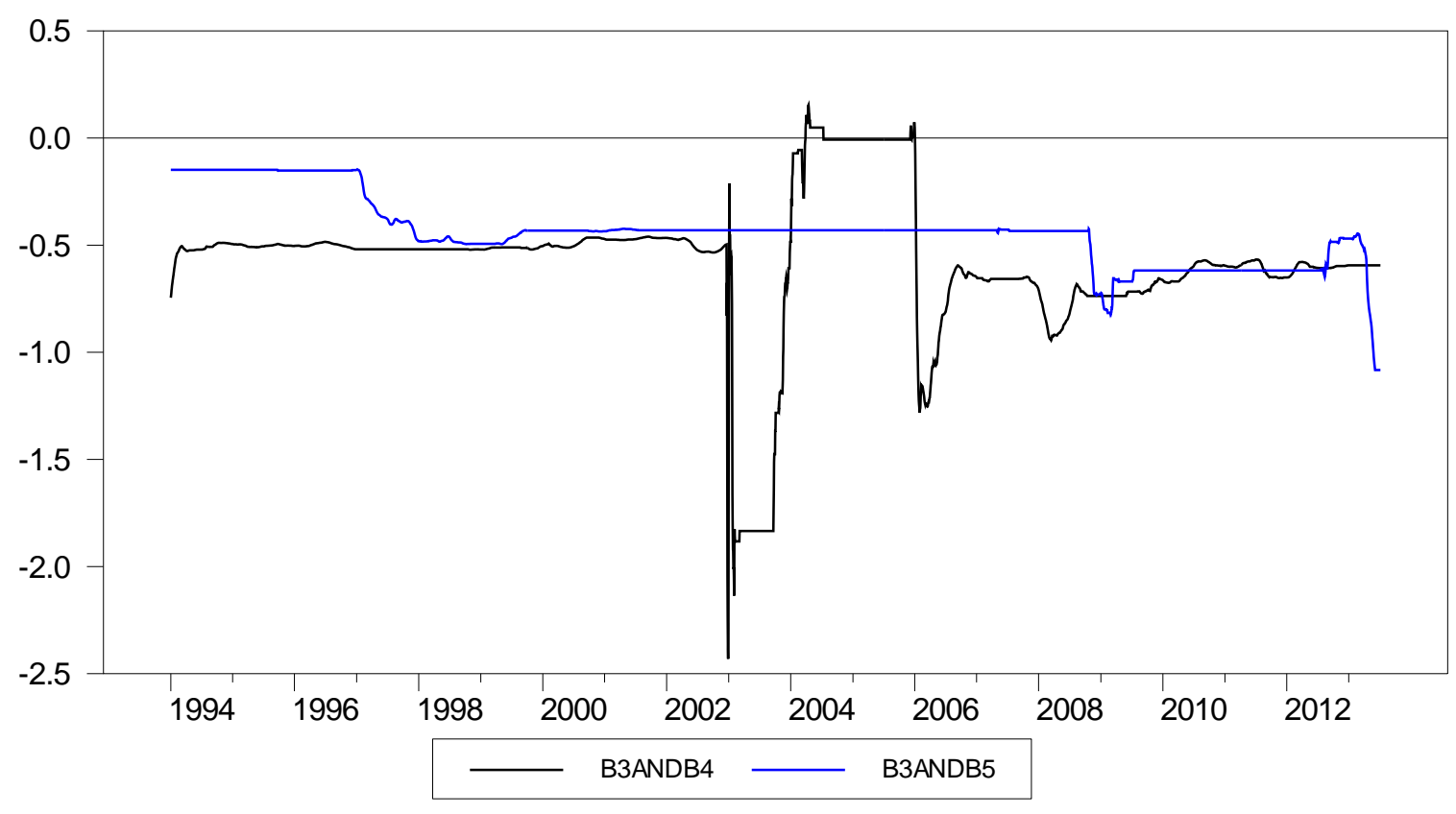

Figure 8: Total Exchange Traded Fund Gold Holdings and PM Fixing, Ounces '000s

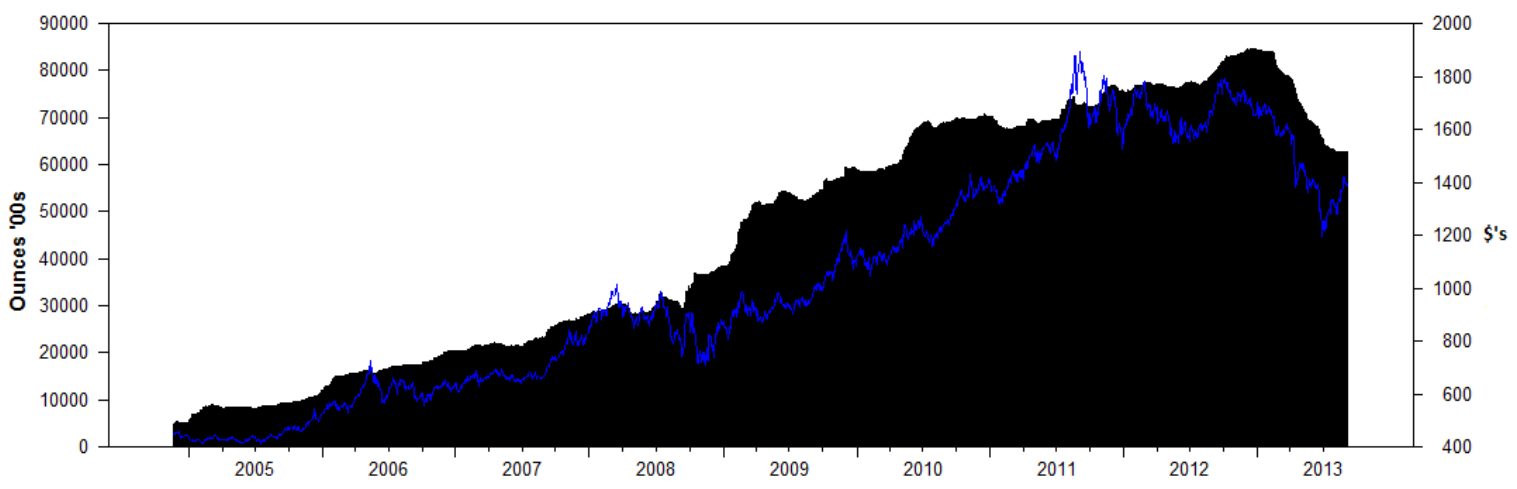

Source: Bloomberg, LBMA 